\title{
A predictive viscosity model for aqueous electrolytes and mixed organic-inorganic aerosol phases
}

\author{
Joseph Lilek ${ }^{1}$ and Andreas Zuend ${ }^{1}$ \\ ${ }^{1}$ Department of Atmospheric and Oceanic Sciences, McGill University, Montréal, Quebec, Canada \\ Correspondence: Andreas Zuend (andreas.zuend@mcgill.ca)
}

\begin{abstract}
Aerosol viscosity is determined by mixture composition and temperature, with a key influence from relative humidity (RH) in modulating aerosol water content. Aerosol particles frequently contain mixtures of water, organic compounds and inorganic ions, so we have extended the thermodynamics-based group-contribution model AIOMFAC-VISC to predict viscosity for aqueous electrolyte solutions and aqueous organic-inorganic mixtures. For aqueous electrolyte solutions, our new,

5 semi-empirical approach uses a physical expression based on Eyring's absolute rate theory, and we define activation energy for viscous flow as a function of temperature, ion activities, and ionic strength. The AIOMFAC-VISC electrolyte model's ionspecific expressions were simultaneously fitted, which arguably makes this approach more predictive than that of other models. This also enables viscosity calculations for aqueous solutions containing an arbitrary number of cation and anion species, including mixtures that have never been studied experimentally. These predictions achieve an excellent level of accuracy while also providing physically meaningful extrapolations to extremely high electrolyte concentrations, which is essential in the context of microscopic aqueous atmospheric aerosols. For organic-inorganic mixtures, multiple mixing approaches were tested to couple the AIOMFAC-VISC electrolyte model with its existing aqueous organic model. We discuss the best performing mixing models implemented in AIOMFAC-VISC for reproducing viscosity measurements of aerosol surrogate systems. We present advantages and drawbacks of different model design choices and associated computational costs of these methods, of importance for use of AIOMFAC-VISC in dynamic simulations. Finally, we demonstrate the capabilities of AIOMFAC-VISC predictions for phase-separated organic-inorganic particles equilibrated to observed temperature and relative humidity conditions from atmospheric balloon soundings. The predictions for the studied cases suggest liquid-like viscosities for an aqueous electrolyte-rich particle phase throughout the troposphere, yet a highly viscous or glassy organic-rich phase in the middle and upper troposphere.
\end{abstract}




\section{Introduction}

\subsection{Viscosity and aerosols}

The dynamic viscosity of various fluids and fluid mixtures is an important material property in industrial applications, cooking, and earth system science at large and small scales. The dynamic viscosity of a fluid characterizes its resistance to flow or deformation; its inverse is known as the fluidity. In the context of aerosol phases, viscosity is also important due to its relationship with the dynamics and timescales of molecular mixing and diffusion (Koop et al., 2011; Reid et al., 2018). At room temperature, liquid water has a dynamic viscosity of approximately $10^{-3} \mathrm{Pas}$; honey one of approximately $10^{1} \mathrm{~Pa}$ s and pitch approximately $10^{8} \mathrm{Pas}$. One can intuitively understand viscosity when attempting to pour each of these fluids out of a container: Water and honey clearly move, albeit at different speeds, while pitch is imperceptibly slow. It is useful to separate the viscosity regimes encountered in aerosol particles and other amorphous solutions into three broad categories, for example as defined by Koop et al. (2011): liquid $\left(<10^{2} \mathrm{Pas}\right)$, semi-solid $\left(10^{2} \mathrm{Pas}-10^{12} \mathrm{Pas}\right)$, and amorphous solid or glassy $\left(>10^{12} \mathrm{Pas}\right)$.

Aerosols impact climate and public health. Natural and anthropogenic processes introduce immense quantities of primary and secondary aerosols into the atmosphere, including organic and elemental carbon, sulfates, nitrates, chlorides, and other inorganic material. Reactive organic compounds can form secondary organic aerosol (SOA), which can homogeneously nucleate or deposit onto preexisting aerosol (Hallquist et al., 2009; Heald and Kroll, 2020). Aerosol particles often contain a mixture of inorganic and organic matter (Zhang et al., 2007); this is especially true in urban environments (Fu et al., 2012). As relative humidity (RH) changes, organic-inorganic mixtures will uptake or release water, which changes the concentration of solutes such as inorganic electrolytes and can potentially induce liquid-liquid phase separation (LLPS) (Shiraiwa et al., 2013); in fact, the individual "liquid" phases could also be semi-solid or even glassy in terms of viscosity.

At very high RH (including water supersaturation), aerosol particles may uptake water to the point where they become or remain homogeneously mixed liquid-like solution droplets while at lower $\mathrm{RH}$, phase separation can occur and one or more of these phases can become relatively viscous. Such RH-dependent viscosity transitions have been observed in laboratory experiments of surrogate aerosol mixtures and reproduced in modelling studies (Reid et al., 2018). That aerosols can be highly viscous under certain conditions has raised a number of interesting questions. Does a high viscosity in an aerosol phase significantly impact the rates of heterogeneous oxidation, multiphase chemistry, or ion-displacement reactions (Zhou et al., 2019; Fard et al., 2017)? How does viscosity affect the equilibrium timescale of gas-particle partitioning for semivolatile organic compounds (Shiraiwa and Seinfeld, 2012)? Does high viscosity substantially slow the rate of water uptake and release (Wallace and Preston, 2019)? And under what environmental conditions and for which chemical compositions do we observe

50 a glassy aerosol state (Zobrist et al., 2008; Koop et al., 2011)? Predictive viscosity models that can accommodate the varied chemistry and non-ideal behavior of aerosol mixtures should allow us to quantify these effects. 


\subsection{Two popular frameworks: Jones-Dole and Eyring}

The two main theoretical frameworks for viscosity of aqueous electrolyte solutions are the Jones-Dole and the Eyring equations. The Jones-Dole equation is one of the earliest identified relationships for relative viscosity and is expressed as

$55 \eta_{\mathrm{rel}}=\frac{\eta_{\mathrm{exp}}}{\eta_{0}}=1+A \sqrt{c}+B c$,

where $\eta_{\text {rel }}$ is the relative (dynamic) viscosity, $\eta_{\exp }$ is the measured viscosity, $\eta_{0}$ is the pure component viscosity of the reference solvent, $c$ is the molarity of the dissolved electrolyte before dissociation, $A$ is a semi-empirical constant that represents the longrange electrostatic forces between ions in solution described by Debye-Hückel theory, and $B$ is the Jones-Dole coefficient (or sometimes simply called the $B$-coefficient), an empirical constant that defines the contribution from short-range ion-solvent interactions to the viscosity of the solution (Jones and Dole, 1929). $A$ and $B$ have been calculated for many electrolytes and at many temperatures, with values available in the literature. The original Jones-Dole equation is only useful for dilute electrolyte solutions, but later extensions added parameters and terms to extend the concentration range in which it is applicable (Kaminsky, 1957; Lencka et al., 1998; Wang et al., 2004). The use of a reference electrolyte assumption can also be used to solve for ionic $B$-coefficients. For example, $\mathrm{KCl}$ contains a cation and an anion of roughly the same size and charge magnitude. Therefore, the $B$-coefficient for $\mathrm{KCl}$ can be evenly split into contributions for $\mathrm{K}^{+}$and $\mathrm{Cl}^{-}$that both equal $\frac{1}{2} B_{\mathrm{KCl}}$ (Cox et al., 1934; Kaminsky, 1957). B-coefficents for many ions have been calculated using the same basic approach (Jenkins and Marcus, 1995).

Glasstone et al. (1941) introduced another equation for viscosity based on absolute rate theory, which we call the Eyring equation:

$70 \eta=\frac{h N_{\mathrm{A}}}{V} e^{\Delta g^{*} /(R T)}$

Here, $h$ is the Planck constant, $N_{\mathrm{A}}$ is Avogadro's constant, $R$ is the universal gas constant and $T$ is the solution temperature in K. $V$ is the average molar volume of the solution. The molar Gibbs energy of activation for viscous flow, $\Delta g^{*}$ (units of $\mathrm{J} \mathrm{mol}^{-1}$ ), is a non-measurable term that can be calculated for liquids for which the viscosity is known or split into additive contributions. The Eyring equation has been tested extensively in earlier works (Goldsack and Franchetto, 1977a, b, 1978; Esteves et al., 2001; Hu and Lee, 2003; Bajić et al., 2014), and has been shown to accurately predict viscosity to higher concentrations than the Jones-Dole equation. The Eyring equation is therefore more attractive for fields that demand accurate viscosity predictions over the full range from highly dilute to highly concentrated aqueous solutions, such as applications in atmospheric aerosols.

\subsection{Our model: AIOMFAC-VISC}

AIOMFAC-VISC, the model applied and further extended in this study, was first introduced by Gervasi et al. (2020) as a thermodynamics-based model for predicting the viscosity of aqueous organic mixtures. In this work, we extend the AIOMFACVISC model for the prediction of the viscosity of aqueous electrolyte solutions, obtaining a level of accuracy close to that of 
the engineering-oriented empirical model developed by Laliberté (2007), while using fewer parameters and a more physicallyjustifiable equation. Moreover, we enable AIOMFAC-VISC to predict viscosity for aqueous organic-inorganic mixtures applicable to aerosol phases across the the observed meteorological ranges of temperature, $\mathrm{RH}$, and chemical composition. "AIOMFAC-VISC" refers to the full viscosity model, which comprises "the electrolyte model" and "the organic model." This distinction becomes especially important when considering aqueous organic-inorganic mixtures.

AIOMFAC-VISC is contained within the Aerosol Inorganic-Organic Mixtures Functional groups Activity Coefficients (AIOMFAC) model, a group-contribution thermodynamic model which explicitly describes the interaction of organic compounds, inorganic ions, and water (Zuend et al., 2008, 2011). AIOMFAC can be run for specific mixture compositions and temperatures as a standalone activity coefficient model or as part of an extended equilibrium framework to compute equilibrium gas-particle partitioning, including LLPS predictions (Zuend et al., 2010; Zuend and Seinfeld, 2012; Pye et al., 2018, 2020). In the latter case, the fully developed AIOMFAC-VISC model, detailed in the next sections, allows for the prediction of viscosities in coexisting liquid, semi-solid, or amorphous solid phases containing water, organic compounds, and inorganic ions.

\section{Theory}

\subsection{Applying Eyring's basis for aqueous electrolyte viscosity in AIOMFAC-VISC}

Using a known value for the viscosity of pure water, $\eta_{\mathrm{w}}$, Eq. (2) becomes

$\Delta g_{\mathrm{w}}^{*}=R T \ln \left(\frac{\eta_{\mathrm{w}} V_{\mathrm{w}}}{h N_{\mathrm{A}}}\right)$

where $V_{\mathrm{w}}$ and $\Delta g_{\mathrm{w}}^{*}$ are the average molar volume and average molar Gibbs energy of activation for viscous flow of pure water. In aqueous electrolyte solutions, knowing $\Delta g_{\mathrm{w}}^{*}$ and $V_{\mathrm{w}}$ allows us to solve algebraically for the $\Delta g^{*}$ and $V$ contributions of the dissolved ions. Goldsack and Franchetto (1977b) split these contributions as

$\Delta g^{*}=x_{\mathrm{w}} \Delta g_{\mathrm{w}}^{*}+\sum_{i=1}^{J} x_{i} \Delta g_{i}^{*}$

105 and

$V=x_{\mathrm{w}} V_{\mathrm{w}}+\sum_{i=1}^{J} x_{i} V_{i}$.

Here, $J$ is the number of different kinds of ions in the mixture, $x_{i}$ is the mole fraction of ion $i$ defined on the basis of dissociated ions, and $x_{\mathrm{w}}$ is the mole fraction of water. Ionic $\Delta g^{*}$ contributions can be calculated, as has been previously shown for $B$ coefficients (Goldsack and Franchetto, 1977b).

Equation (2) depends on the molar Gibbs energy of activation for viscous flow, a quantity that can be estimated but is not directly measurable. According to Eyring, viscosity can be conceptualized as the transient formation and refilling of holes 
in a fluid as molecules or ions diffuse through the fluid interior. This concept informs our model design. While Goldsack and Franchetto (1977b) used a modified form of the Eyring equation that emphasized binary and ternary mixtures, AIOMFACVISC accommodates an arbitrary number of cation and anion species in any proportion and with the added benefit of some level of predictability for aqueous electrolyte systems containing ions in combinations that have never been studied experimentally.

\subsection{Deriving an expression for the molar Gibbs energy for viscous flow}

Equation (2) provides an expression for mixture viscosity that depends on an effective average molar Gibbs energy of activation - see Eq. (4). Since the molar Gibbs energy of activation for viscous flow of a single ionic species, e.g. $\mathrm{Na}^{+}$, cannot be measured and using the reference electrolyte assumption would introduce too much uncertainty, we turn to thermodynamic theory to define an equation to estimate it. First, consider the molar Gibbs energy contribution of an ionic species to a thermodynamic phase at constant temperature and pressure, $g_{i}=\mu_{i}$, where $\mu_{i}$ is the chemical potential of ion $i$. Analogously, we can introduce a molar Gibbs energy of activation for viscous flow, $g_{i}^{*}$. This activated-state energy can be compared to an inactivated reference state (representing equilibrium conditions), $g_{i}^{r e f}$, such that $\Delta g_{i}^{*}$ is defined as

$\Delta g_{i}^{*}=g_{i}^{*}-g_{i}^{r e f}$,

or equivalently,

$\Delta g_{i}^{*}=\mu_{i}^{*}-\mu_{i}^{r e f}$.

$\mu_{i}^{*}$ and $\mu_{i}^{r e f}$ can be expressed as

$\mu_{i}=\mu_{i}^{\circ,(m)}\left(p^{\circ}, T, m^{\circ}\right)+R T \ln \left[a_{i}^{(m)}\right]$,

where $\mu_{i}^{\circ}$ is the standard-state chemical potential, and $R T \ln \left[a_{i}^{(m)}\right]$ is a correction term that depends on the ion activity, $a_{i}^{(m)}$, with superscript $(m)$ denoting activity defined on a molality basis. For ions it is common to use a molality basis, such that the ion activity, $a_{i}$, is defined as the molality of the ion, $m_{i}$, normalized by unit molality, $m^{\circ}=1 \mathrm{~mol} \mathrm{~kg}^{-1}$, and multiplied by the activity coefficient of the ion, $\gamma_{i}$ (e.g. Zuend et al., 2008):

$a_{i}^{(m)}=\frac{m_{i}}{m^{\circ}} \gamma_{i}^{(m)}$.

AIOMFAC defines ion molality as moles of dissociated ion per $1 \mathrm{~kg}$ of solvent mixture (water + organics) as opposed to per $1 \mathrm{~kg}$ of water, and this must be taken into account when organics are present. For the sake of simpler notation, we will hereafter omit superscript $(m)$ as molality basis will consistently be used for all ions in this work. Equation (7) then becomes

$\Delta g_{i}^{*}=\mu_{i}^{\circ, *}+R T \ln \left[a_{i}^{*}\right]-\mu_{i}^{\circ, r e f}+R T \ln \left[a_{i}^{r e f}\right]$.

During viscous flow, the standard-state chemical potential does not change and we define $\mu_{i}^{\circ, *}=\mu_{i}^{\circ, r e f}$. Therefore, Eq. (10) simplifies to 
or simpler still,

$$
\frac{\Delta g_{i}^{*}}{R T}=\ln \left(\frac{a_{i}^{*}}{a_{i}^{r e f}}\right) .
$$

The problem shifts from defining the molar Gibbs energy for viscous flow to quantifying the activation activity for viscous flow. It is assumed that this special activity $a_{i}^{*}$ is a function of the reference activity, $a_{i}^{r e f}$. Therefore, $a_{i}^{*}=f\left(a_{i}^{r e f}\right)$, which by Eq. (9) implies dependence on $\gamma_{i}^{r e f}$ and the molality, $m_{i}$. Thus, $\frac{\Delta g_{i}^{*}}{R T}=f\left(\gamma_{i}^{r e f}, m_{i}\right)$.

\subsection{Contributions to Gibbs energy for viscous flow}

In our model, this energy is decomposed into three component-specific, additive contributions. First, the energy required for solvent molecules to move from their original locations into vacant holes, or to form new holes, is the molar Gibbs energy for viscous flow of the solvent, $\Delta g_{\mathrm{w}}^{*}$. Here we focus on water as the only solvent of ions for the purpose of this part of the AIOMFAC-VISC model for aqueous electrolyte solutions; mixtures of water, organics, and ions will be considered in Sect. 3.4. Second, the energy required for dissolved ions to move from their original locations into vacant holes is the molar Gibbs energy for viscous flow of the ions, $\Delta g_{i}^{*}$. Third, in highly concentrated solutions, cations and anions can interact sufficiently frequently that they can impact the viscosity of the solution. The energy required for temporarily coupled cation-anion entities to move from their original locations into vacant holes is the molar Gibbs energy for viscous flow for cation-anion pairs, $\Delta g_{c, a}^{*}$. Finally, Eq. (3) is used to define the molar activation energy for viscous flow for water.

\subsubsection{Gibbs energy contributions from ions and cation-anion pairs}

Each individual ion is assigned two coefficients, $c_{0, i}$ and $c_{1, i}$, and we express $\frac{\Delta g_{i}^{*}}{R T}$ by the functional form

$\frac{\Delta g_{i}^{*}}{R T}=c_{0, i} \ln \left(a_{i}^{r e f}\right)+c_{1, i}$.

Here, $a_{i}^{r e f}$ is considered to be the molal ion activity for the given mixture composition, e.g. computed with AIOMFAC. Initial tests indicated that the use of a single fit parameter per ion would provide inadequate flexibility for the model to fit experimental data, so a second parameter was included in Eq. (13). In our approach, we have no need for a reference electrolyte assumption, as molar Gibbs energy for viscous flow is defined for each ion, not each electrolyte. Note that Eq. (13) is consistent with the functional form of Eq. (12); we can write the right-hand side of Eq. (13) equivalently as $\ln \left[\left(a_{i}^{r e f}\right)^{c_{0, i}} \cdot \exp \left(c_{1, i}\right)\right]$ and comparison to Eq. (12) identifies $a_{i}^{*}$ as $a_{i}^{*}=\left(a_{i}^{r e f}\right)^{c_{0, i}+1} \cdot \exp \left(c_{1, i}\right)$. Each cation-anion pair is assigned a single coefficient, $c_{c, a}$ and $\Delta g_{c, a}^{*}$ is a function of the square root of molal ionic strength,

$\frac{\Delta g_{c, a}^{*}}{R T}=c_{c, a} \sqrt{I}$

Molal ionic strength $I$ is defined as

$$
I=\frac{1}{2} \sum_{i}^{N} m_{i} z_{i}^{2},
$$


where $m_{i}$ is the molality and $z_{i}$ the integer (relative) electric charge of ion $i$. Equation (14) is inspired by similar expressions used for Pitzer-based ion activity coefficient expressions, such as those within AIOMFAC (Zuend et al., 2008).

\subsubsection{Adding up the Gibbs energy contributions}

The full expression for the molar Gibbs energy change for viscous flow of an aqueous electrolyte solution is related to Eq. (4) and fits directly into the exponential function in Eq. (2); it consists of the weighted contributions from Eqs. (3), (13), and (14), covering all individual ions and all possible binary cation-anion combinations in the solution,

$\frac{\Delta g^{*}}{R T}=x_{\mathrm{w}} \frac{\Delta g_{\mathrm{w}}^{*}}{R T}+\sum_{i=1}^{J}\left(x_{i} \frac{\Delta g_{i}^{*}}{R T}\right)+\sum_{c=1}^{J_{c}} \sum_{a=1}^{J_{a}}\left(\tau_{c, a} \frac{\Delta g_{c, a}^{*}}{R T}\right)$.

Here, $\tau_{c, a}$ is a special weighting term that accounts for contributions from all possible binary cation-anion pairs in a chargeand abundance-balanced manner. This can be accomplished by treating the aqueous solution as a mixture of charge-neutral cation-anion pairs, with each cation combined with each anion proportionally to the ion amounts involved. Consider the total positive charge in the aqueous electrolyte mixture, $\sum_{c=1}^{J_{c}} x_{c} \cdot z_{c}$, which is equivalent to the total negative charge, $\sum_{a=1}^{J_{a}} x_{a} \cdot\left|z_{a}\right|$, for an overall charge-neutral solution. We can define the charge fraction $\psi_{a}$ as the absolute amount of charge contributed by anion $a$ relative to the sum of absolute charge contributions of all negative charges present (or alternatively, relative to the sum of all positive ones) in the mixture,

$\psi_{a}=\frac{x_{a} \cdot\left|z_{a}\right|}{\sum_{a^{\prime}=1}^{J_{a}} x_{a^{\prime}} \cdot\left|z_{a^{\prime}}\right|}$,

and the weighting term,

$\tau_{c, a}=\frac{x_{c}}{\nu_{c, e l}} \cdot \psi_{a}$

$\tau_{c, a}$ represents the fractional amount of the hypothetical, neutral electrolyte component $e l$ consisting of cation $c$ and anion $a$, where $\nu_{c, e l}$ is the stoichiometric number of cations in a formula unit of this electrolyte. This treatment is further described in the Supplemental Information (SI), in Sect. S1. Temporary cation-cation and anion-anion pairs are unlikely to form to the same extent because similarly charged ions will repel each other. Pitzer models show that to a first-order approximation, those interactions can be neglected (e.g. Zuend et al., 2008).

Some considerations bear mentioning. $\frac{\Delta g_{\mathrm{w}}^{*}}{R T}$ is a unitless quantity related through Eq. (3) to the viscosity of pure water. At $298.15 \mathrm{~K}$, pure water has a viscosity of $8.9 \times 10^{-4} \mathrm{Pas}$, and $\frac{\Delta g^{*}}{R T}=3.44$. If the total Gibbs energy for viscous flow drops below this threshold, the Eyring equation will calculate a viscosity less than that of pure water. For certain aqueous electrolyte solutions that have a local viscosity minimum in the dilute range, this is a necessary condition. When $a_{i}^{\text {ref }}$ values are less than one, the ionic contribution can become negative, allowing $\frac{\Delta g^{*}}{R T}<3.44$. To avoid viscosity values that are too low, the cation-anion contribution may compensate by being more positive. This interplay of viscosity contributions from water, ions, and cation-anion interactions is delicate, and requires optimized coefficients. To avoid negative $\frac{\Delta g^{*}}{R T}$ and nonphysical behavior, we determined that all AIOMFAC-VISC coefficients should be positive real numbers. 


\subsection{Representing volume, charge, and hydration effects on viscosity}

The effective size of the dissolved ions impacts the amount of Gibbs energy needed to activate viscous flow. Conceptually, if ions have small volumes, they slip relatively easily through the intermolecular network and into available/generated openings, displacing very few water molecules in the process; this would correspond to low viscosity. By contrast, large ions must displace more neighboring (solvent) molecules, which requires more energy temporarily and indicates higher viscosity. If an ion has a high charge density - the ratio of charge to ion volume - it will strongly attract water molecules into a temporary hydration shell, increasing the apparent size of the moving ion. Conversely, if an ion has low charge density, this hydration effect is reduced, sometimes negligible. In AIOMFAC-VISC, as part of the original AIOMFAC model, hydrated volumes are used for ions, ensuring that hydration effects are included where they are important. Ions in aqueous solutions with a strong hydration effect are termed "structure-making," while those with a large ionic volume and weak hydration effect are "structurebreaking" (Marcus, 2009). This behavior is also observed in the low-concentration mixture viscosity minimum observed in the viscosity curves of aqueous solutions of structure-breaking ions like $\mathrm{K}^{+}$and $\mathrm{NH}_{4}^{+}$, but not those of structure makers like $\mathrm{Li}^{+}$ and $\mathrm{Mg}^{2+}$ (as later shown in Fig. 2).

\subsubsection{Molar volume of solution}

We define the effective mean molar volume of the solution, $V$, as the mole-fraction-weighted mean of the pure-component molar volumes of the solvent and the dissolved ions, as in Eq. (5). A volume correction, $c_{v}$, is defined for the model and applied in all instances as

$V=x_{\mathrm{w}} V_{\mathrm{w}}+c_{v} \sum_{i=1}^{J} x_{i} V_{i}$.

The $c_{v}$ term is included to account for potential discrepancies in attributed ionic volumes, some of which include partial hydration effects. AIOMFAC uses relative van der Waals volumes, which are calculated by solving for the volume of a sphere of radius $r_{c}$ and dividing by $15.17 \times 10^{-6} \mathrm{~m}^{3} \mathrm{~mol}^{-1}$, the volume of a reference subgroup (Abrams and Prausnitz, 1975; Fredenslund et al., 1975). The reference subgroup is used to calculate relative volumes for neutral molecules as well. For example, the relative volume for $\mathrm{H}_{2} \mathrm{O}$ is 0.92 , since $\left(1.3956 \times 10^{-5} \mathrm{~m}^{3} \mathrm{~mol}^{-1}\right) /\left(15.17 \times 10^{-6} \mathrm{~m}^{3} \mathrm{~mol}^{-1}\right) \approx 0.92$. Values for the volumes and hydration numbers for the ions used in AIOMFAC-VISC are included in Table 1.

\section{Data and Methods}

\subsection{Available viscosity measurements}

At present, AIOMFAC can predict activity coefficients for a large number of atmospherically relevant cations and anions (Yin et al., 2021), including the seven cations $\left(\mathrm{H}^{+}, \mathrm{Li}^{+}, \mathrm{Na}^{+}, \mathrm{K}^{+}, \mathrm{NH}_{4}^{+}, \mathrm{Mg}^{2+}, \mathrm{Ca}^{2+}\right)$ and six anions $\left(\mathrm{Cl}^{-}, \mathrm{Br}^{-}, \mathrm{NO}_{3}^{-}, \mathrm{HSO}_{4}^{-}\right.$, $\mathrm{SO}_{4}^{2-}, \mathrm{I}^{-}$) considered for this study. Therefore, we used viscosity measurements for aqueous electrolyte systems that included 
Table 1. Relative van der Waals ionic volume $\left(R_{t}^{H}\right)$ parameters for cations and anions considering apparent dynamic hydration. Table adapted from Zuend et al. (2008).

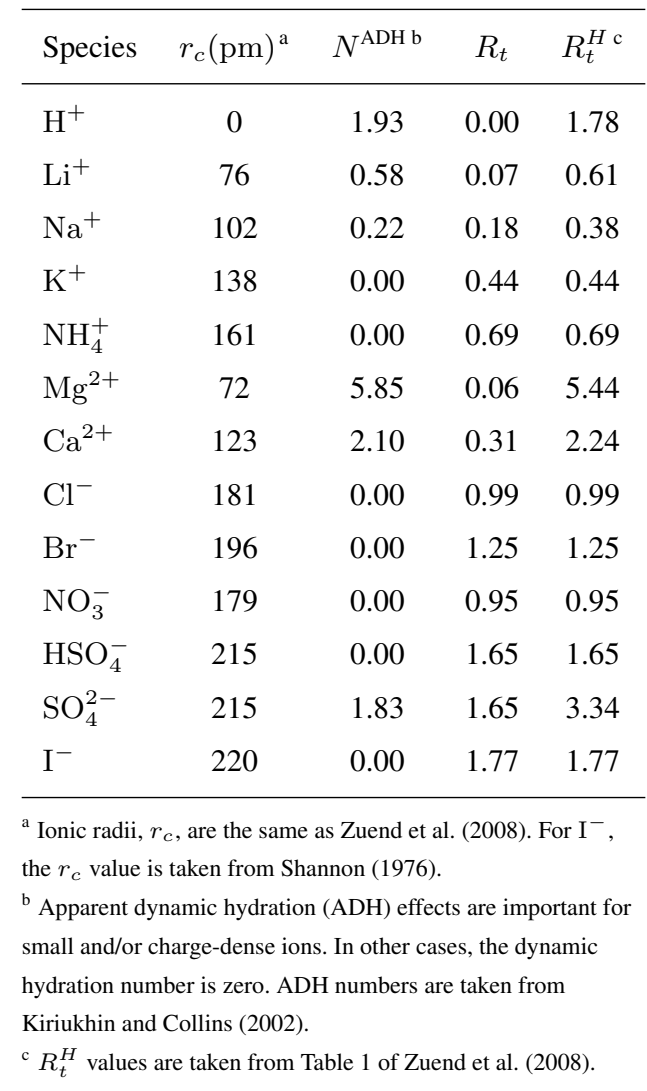

combinations of these ions. Forty-three such systems were identified and used to fit the model. Ongoing work is extending AIOMFAC for additional ions of special relevance to aerosol particles, and future versions of AIOMFAC-VISC may include these ions. Bulk measurements (i.e. those taken with a conventional viscometer or rheometer) for 28 binary systems were used to fit AIOMFAC-VISC, 26 of which were previously aggregated by Laliberté (2007); detailed references for these 26 systems are included in that article and its electronic supplement. Bulk data from 15 ternary and quaternary aqueous electrolyte systems were also used. Finally, three data sets of droplet-based measurements are included from Song et al. (2021) and Baldelli et al. (2016). The aggregated data include measurements at temperatures ranging from 263.15 to $427.15 \mathrm{~K}$. Points at temperatures greater than $333 \mathrm{~K}$ were excluded from our model fit, to avoid biasing the model toward relatively high temperatures and because it is unlikely that aerosols will experience temperatures above $333 \mathrm{~K}$ in Earth's atmosphere. Ultimately, 6,625 data points were used to fit the AIOMFAC-VISC electrolyte model.

Data availability varies considerably across systems. The systems with the most data are aqueous $\mathrm{KCl}, \mathrm{NaCl}, \mathrm{LiCl}$, and $\mathrm{CaCl}_{2}$ - each with more than 500 points. The mean number of data points per data set is 144 , but some systems like $\mathrm{HCl}$, $\mathrm{HNO}_{3}$, and $\mathrm{NaHSO}_{4}$ each contain fewer than 20 points. As shown in Figs. 4-7, most viscosity measurements are clustered 
in the dilute concentration range. In fact, less than $4 \%$ of the viscosity measurements used to fit AIOMFAC-VISC are at mass fractions of water below 0.5. The highest available mass concentrations for bulk measurements were for $\mathrm{Ca}\left(\mathrm{NO}_{3}\right)_{2}$, $\mathrm{H}_{2} \mathrm{SO}_{4}$, and $\mathrm{NH}_{4} \mathrm{NO}_{3}$, where measurements are available to mass fractions of water below 0.3 (solute mass fractions above 0.7). Some systems remain close to the viscosity of pure water throughout the concentration range, while others span multiple orders of magnitude - see the right two columns of Table 2. For pure water at $298 \mathrm{~K}, \log _{10}\left(\eta / \eta^{\circ}\right)=-3.054$. Structurebreaking electrolytes can be identified where $\log _{10}\left(\eta / \eta^{\circ}\right)_{\text {min }}$ is less than $-3.054 . \mathrm{Ca}\left(\mathrm{NO}_{3}\right)_{2}$ includes the greatest range, with viscosities between $10^{-4}$ and $10^{-1} \mathrm{Pas}$, and approaching even higher values for the most concentrated solutions observed in laboratory experiments. While still in the liquid-like viscosity range, these high concentration data are of particular interest for aerosol modelling. More recently, techniques such as poke-and-flow, bead mobility, and holographic optical tweezers have enabled viscosity measurements for droplets (Reid et al., 2018). Due to their small size and absence of contact with solid surfaces, aqueous droplets often attain concentrations of solute exceeding the bulk solubility limits, suggesting higher viscosities are likely to occur in nature.

\subsubsection{Viscosity temperature dependence}

Viscosity is strongly temperature dependent, and some viscosity models define their coefficients differently at each temperature, such as with the $B$-coefficients. AIOMFAC-VISC does not do this. We posit that the temperature-dependent pure-component viscosity of water already sufficiently captures the temperature dependence of aqueous electrolyte mixtures. Moreover, the AIOMFAC-VISC coefficients are assumed to be temperature-independent. In fitting AIOMFAC-VISC, we include measurements from $263 \mathrm{~K}$ to $333 \mathrm{~K}$, and we use the same model coefficients at all temperatures. Including the data for multiple temperatures reduced the fit residuals considerably, when compared to a fit that only included data at temperatures at or near 298 K. Finally, AIOMFAC-VISC uses ion activity values from AIOMFAC that are optimized for a temperature of 298.15 K. Activity coefficients are weakly temperature dependent, so AIOMFAC-VISC predictions outside the $298 \pm 30 \mathrm{~K}$ range may also be less reliable. To illustrate the temperature dependence of viscosity, measurements (and AIOMFAC-VISC predictions) are shown in Fig. S8 for several binary aqueous electrolyte solutions at selected temperatures within the range from $268 \mathrm{~K}$ to $328 \mathrm{~K}$.

\subsubsection{Error in viscosity measurements}

Viscosity measurement error is rarely reported for bulk measurements, especially in publications before 1990. Where values do exist, they vary widely. For example, Roy et al. (2004) claims $0.05 \%$ error in kinematic viscosity measurements. Abdulagatov et al. (2004) describes $1.5 \%$ error in viscosity measurements for aqueous calcium nitrate solutions. Zhang and Han (1996) describe the accuracy as within $0.05 \%$ for their viscosity measurements of aqeuous $\mathrm{NaCl}$ and $\mathrm{KCl}$ solutions. Wahab and Mahiuddin (2001) reported an error of $0.5 \%$ for aqueous calcium chloride solutions. A proxy for viscosity error is the scatter of our training data. Viscosity values measured at the same temperature and nearly identical concentrations show considerable scatter in multiple data sets (e.g., $\mathrm{K}_{2} \mathrm{SO}_{4}, \mathrm{NaNO}_{3}$, and $\mathrm{KBr}$; see Fig. S8), likely owing to different measurement techniques and/or measurement, calibration, and transcription error. Laliberté (2007) found the standard deviation of their viscosity resid- 
ual to be $3.7 \%$ of the average experimental viscosity for 74 data sets consisting of over 9,000 data points in total. Due to the wide range of reported errors for viscosity and the scatter among measurements at similar concentrations, we decided to treat all measurements as if they included a $2 \%$ error. This $2 \%$ error is also included in the objective function used to fit the model. Displayed on a logarithmic scale, this error for bulk viscosity measurements is generally smaller than the size of plotted symbols, so error bars are mostly not shown. See Tables 2-4 for information on the temperature, concentration, and viscosity ranges of these data sets. The error for droplet-based viscosity measurements is typically larger than the error in bulk measurements, in part owing to the difficulty of precisely knowing the water content of the droplets (at a certain RH) examined with these techniques.

\subsection{Simultaneously fitting the AIOMFAC-VISC electrolyte model}

We used a combination of global optimization methods to simultaneously fit the $c_{v}, c_{0, i}, c_{1, i}$, and $c_{c, a}$ coefficients based on the ions and cation-anion pairs described by 33 aqueous electrolyte systems. All single-ion coefficients were fitted to data from multiple systems, e.g., $c_{0, \mathrm{~K}^{+}}$and $c_{1, \mathrm{~K}^{+}}$are simultaneously fitted to all data points that include the $\mathrm{K}^{+}$ion. First, we used a method described by Zuend et al. (2010) called "best-of-random differential evolution" (BoRDE), which is based on the Differential Evolution algorithm by Storn and Price (1997), a robust global optimization method. To implement BoRDE, we borrowed code from Zuend et al. (2010). After honing in on the coefficients with BoRDE, we switched to the constrained global optimization method (GLOBAL) by Csendes (1988), which implements the Boender-Rinnooy Kan-Stougie-Timmer algorithm in Fortran (Boender et al., 1982). The Fortran 90 version of GLOBAL is freely available online (Miller, 2003). GLOBAL identifies clusters of local minima to efficiently survey the parameter space, sometimes substantially improving upon the solution found by BoRDE. Inherent in both the GLOBAL and BoRDE fitting processes is an objective function, which is used to evaluate the model performance for a given set of the adjustable coefficients, where a smaller objective function value indicates a better model fit to the data. This function often takes the form of a residual or error equation, such as root mean square error, but it can also be customized to suit the data and the intended use of the model. Our objective function is described in Sect. 4.

\subsection{Implementation for aqueous electrolyte systems}

The AIOMFAC-VISC electrolyte model equations and coefficients have been implemented in Fortran and included as an optional module within the larger AIOMFAC model framework. The electrolyte model is incorporated alongside the aqueous organic viscosity model by Gervasi et al. (2020). AIOMFAC calculates activity coefficients for all components in a mixture based on activity coefficient contributions from long-range, middle-range, and short-range molecular interactions. Those three contributions include effects from dissolved ions, so it is essential that viscosity calculations for aqueous electrolyte solutions proceed after these contributions have been calculated. A number of input quantities are needed prior to calling the aqueous electrolyte solution viscosity module within AIOMFAC, including the calculation of the pure-component viscosity of water at given temperature, for which the parameterization by Dehaoui et al. (2015) is used. The mole fractions of water and the ions, the activity coefficients, and the relative ionic volumes are all available through the AIOMFAC interface, computed by various 
Table 2. Data set information for bulk measurements of binary aqueous electrolyte solutions used to fit the AIOMFAC-VISC electrolyte model. All data have been aggregated by Laliberté $(2007,2009)$ unless otherwise noted.

\begin{tabular}{|c|c|c|c|c|c|c|c|}
\hline Electrolyte & $N$ & $T_{\min }$ & $T_{\max }$ & $T_{\text {mean }}$ & $w_{\mathrm{w}, \min }{ }^{\mathrm{a}}$ & $\log _{10}\left(\eta / \eta^{\circ}\right)_{\max }^{\mathrm{b}}$ & $\log _{10}\left(\eta / \eta^{\circ}\right)_{\min }^{\mathrm{b}}$ \\
\hline $\mathrm{KCl}$ & 585 & 278.15 & 333.15 & 304.82 & 0.6944 & -2.962 & -3.056 \\
\hline $\mathrm{NaCl}$ & 479 & 278.15 & 333.15 & 304.58 & 0.7355 & -2.718 & -3.050 \\
\hline $\mathrm{LiCl}$ & 581 & 268.15 & 333.15 & 300.15 & 0.5400 & -1.751 & -3.047 \\
\hline $\mathrm{NH}_{4} \mathrm{Cl}$ & 259 & 283.15 & 333.15 & 305.89 & 0.6757 & -2.991 & -3.058 \\
\hline $\mathrm{CaCl}_{2}$ & 485 & 273.15 & 333.15 & 302.69 & 0.4868 & -1.468 & -3.047 \\
\hline $\mathrm{NaNO}_{3}$ & 338 & 283.15 & 333.15 & 308.79 & 0.4479 & -2.524 & -3.049 \\
\hline $\mathrm{NH}_{4} \mathrm{NO}_{3}$ & 277 & 288.15 & 333.15 & 304.47 & 0.2151 & -2.725 & -3.072 \\
\hline$\left(\mathrm{NH}_{4}\right)_{2} \mathrm{SO}_{4}$ & 148 & 288.15 & 333.15 & 307.35 & 0.5371 & -2.588 & -3.047 \\
\hline $\mathrm{Na}_{2} \mathrm{SO}_{4}$ & 200 & 288.15 & 333.15 & 305.84 & 0.6687 & -2.661 & -3.050 \\
\hline $\mathrm{NaBr}$ & 217 & 278.15 & 333.15 & 306.02 & 0.4595 & -2.564 & -3.050 \\
\hline $\mathrm{MgSO}_{4}$ & 166 & 288.15 & 333.15 & 304.20 & 0.7015 & -2.092 & -3.050 \\
\hline $\mathrm{Mg}\left(\mathrm{NO}_{3}\right)_{2}$ & 214 & 273.15 & 323.15 & 300.52 & 0.5607 & -2.153 & -3.042 \\
\hline $\mathrm{MgCl}_{2}$ & 319 & 288.15 & 333.15 & 307.59 & 0.6225 & -1.892 & -3.050 \\
\hline $\mathrm{LiNO}_{3}$ & 88 & 273.15 & 333.05 & 299.87 & 0.3764 & -1.878 & -3.051 \\
\hline $\mathrm{Li}_{2} \mathrm{SO}_{4}$ & 147 & 278.15 & 333.15 & 303.30 & 0.7398 & -2.243 & -3.050 \\
\hline $\mathrm{KNO}_{3}$ & 146 & 288.15 & 333.15 & 308.01 & 0.5050 & -2.999 & -3.061 \\
\hline $\mathrm{KBr}$ & 319 & 273.15 & 333.15 & 302.19 & 0.5378 & -2.982 & -3.079 \\
\hline $\mathrm{HCl}$ & 163 & 283.15 & 315.65 & 299.07 & 0.6400 & -2.692 & -3.050 \\
\hline $\mathrm{HBr}$ & 11 & 273.15 & 298.15 & 288.60 & 0.8047 & -3.017 & -3.047 \\
\hline $\mathrm{H}_{2} \mathrm{SO}_{4}$ & 118 & 263.15 & 323.15 & 295.78 & 0.2180 & -1.810 & -3.048 \\
\hline $\mathrm{Ca}\left(\mathrm{NO}_{3}\right)_{2}$ & 135 & 263.15 & 333.00 & 306.57 & 0.3052 & -0.474 & -3.037 \\
\hline $\mathrm{K}_{2} \mathrm{SO}_{4}$ & 188 & 273.15 & 333.15 & 307.85 & 0.8453 & -2.946 & -3.050 \\
\hline KI & 218 & 278.15 & 333.15 & 300.31 & 0.3726 & -2.938 & -3.093 \\
\hline $\mathrm{NaI}$ & 150 & 278.15 & 332.41 & 300.14 & 0.3715 & -2.450 & -3.050 \\
\hline $\mathrm{NaHSO}_{4}$ & 5 & 291.15 & 291.15 & 291.15 & 0.6249 & -2.519 & -2.954 \\
\hline $\mathrm{HNO}_{3}$ & 16 & 277.15 & 298.15 & 290.40 & 0.6915 & -2.880 & -3.045 \\
\hline $\mathrm{HI}^{\mathrm{c}}$ & 77 & 283.15 & 313.15 & 298.15 & 0.4300 & -2.858 & -3.050 \\
\hline $\mathrm{LiBr}^{\mathrm{d}}$ & 19 & 298.06 & 333.17 & 312.57 & 0.4150 & -2.167 & -2.951 \\
\hline
\end{tabular}

${ }^{\mathrm{a}} w_{\mathrm{w}, \min }$ is the minimum mass fraction of water, which corresponds to the highest solute concentration.

${ }^{\mathrm{b}}$ These columns show the maximum and minimum values for $\log _{10}\left(\eta / \eta^{\circ}\right)$ at $\mathrm{T}=295 \pm 5 \mathrm{~K}$, where $\eta^{\circ}$ denotes unit viscosity (1 Pa s).

${ }^{c}$ Data from Nishikata et al. (1981); ${ }^{d}$ data from Wimby and Berntsson (1994).

procedures within the AIOMFAC computer program. Equations (13) - (19) are then evaluated for the system and the mixture's dynamic viscosity is calculated via Eq. (2). 
Table 3. Data set information for bulk measurements of ternary and quaternary aqueous electrolyte mixtures used to fit the AIOMFAC-VISC electrolyte model.

\begin{tabular}{|c|c|c|c|c|c|c|c|}
\hline Electrolyte System & $N$ & $T_{\min }$ & $T_{\max }$ & $T_{\text {mean }}$ & $w_{\mathrm{w}, \min }^{\mathrm{a}}$ & $\log _{10}\left(\eta / \eta^{\circ}\right)_{\max }^{\mathrm{b}}$ & $\log _{10}\left(\eta / \eta^{\circ}\right)_{\min }^{\mathrm{b}}$ \\
\hline $\mathrm{HCl}+\mathrm{KCl}+\mathrm{NaCl}^{\mathrm{c}}$ & 29 & 298.15 & 298.15 & 298.15 & 0.7627 & -2.890 & -3.046 \\
\hline$\left(\mathrm{NH}_{4}\right)_{2} \mathrm{SO}_{4}+\mathrm{Na}_{2} \mathrm{SO}_{4}{ }^{\mathrm{c}}$ & 6 & 298.15 & 298.15 & 298.15 & 0.6666 & -2.697 & -2.913 \\
\hline $\mathrm{KBr}+\mathrm{NaCl}]^{\mathrm{c}}$ & 6 & 298.15 & 298.15 & 298.15 & 0.7031 & -2.943 & -3.044 \\
\hline $\mathrm{KCl}+\mathrm{NaCl}^{\mathrm{c}, \mathrm{e}, \mathrm{h}}$ & 57 & 298.15 & 333.15 & 306.04 & 0.7154 & -2.896 & -3.047 \\
\hline$\left(\mathrm{NH}_{4}\right)_{2} \mathrm{SO}_{4}+\mathrm{KCl}^{\mathrm{c}}$ & 6 & 298.15 & 298.15 & 298.15 & 0.8139 & -2.964 & -3.008 \\
\hline $\mathrm{NaCl}+\mathrm{KBr}+\left(\mathrm{NH}_{4}\right)_{2} \mathrm{SO}_{4}{ }^{\mathrm{c}}$ & 6 & 298.15 & 298.15 & 298.15 & 0.6025 & -2.859 & -2.994 \\
\hline $\mathrm{CaCl}_{2}+\mathrm{NaCl}^{\mathrm{d}}$ & 114 & 298.15 & 298.15 & 298.15 & 0.6957 & -2.531 & -3.048 \\
\hline $\mathrm{NaCl}+\mathrm{NH}_{4} \mathrm{NO}_{3}{ }^{\mathrm{e}}$ & 17 & 298.15 & 298.15 & 298.15 & 0.5079 & -2.740 & -3.053 \\
\hline $\mathrm{NaCl}+\mathrm{Ca}\left(\mathrm{NO}_{3}\right)_{2}{ }^{\mathrm{e}}$ & 18 & 298.15 & 298.15 & 298.15 & 0.5969 & -2.465 & -3.022 \\
\hline $\mathrm{NaCl}+\mathrm{MgSO}_{4}{ }^{\mathrm{e}, \mathrm{h}}$ & 39 & 298.15 & 333.15 & 309.69 & 0.8231 & -2.571 & -3.021 \\
\hline $\mathrm{LiBr}+\mathrm{LiI}^{g}$ & 41 & 283.15 & 333.15 & 308.76 & 0.3450 & -1.917 & -2.947 \\
\hline $\mathrm{LiCl}+\mathrm{LiNO}_{3}{ }^{\mathrm{g}}$ & 30 & 283.15 & 333.15 & 308.15 & 0.4990 & -1.697 & -2.879 \\
\hline $\mathrm{KCl}+\mathrm{CaCl}_{2}{ }^{\mathrm{f}}$ & 118 & 298.15 & 298.15 & 298.15 & 0.6736 & -2.544 & -3.050 \\
\hline $\mathrm{NaCl}+\mathrm{Na}_{2} \mathrm{SO}_{4}{ }^{\mathrm{e}}$ & 28 & 298.15 & 333.15 & 314.76 & 0.8302 & -2.881 & -3.023 \\
\hline $\mathrm{NaCl}+\mathrm{MgCl}_{2}+\mathrm{MgSO}_{4}+\mathrm{KCl}^{\mathrm{h}}$ & 15 & 298.15 & 333.15 & 314.82 & 0.9038 & -2.953 & -3.019 \\
\hline
\end{tabular}

${ }^{\mathrm{a}} w_{\mathrm{w}, \text { min }}$ is the minimum mass fraction of water, which corresponds to the highest solute concentration.

${ }^{\mathrm{b}}$ These columns show the maximum and minimum values for $\log _{10}\left(\eta / \eta^{\circ}\right)$ at $\mathrm{T}=295 \pm 5 \mathrm{~K}$, where $\eta^{\circ}$ denotes unit viscosity (1 Pa s).

${ }^{\mathrm{c}}$ Data from Goldsack and Franchetto (1977a); ${ }^{\mathrm{d}}$ Laliberté (2007, 2009); ${ }^{\mathrm{e}}$ Nowlan et al. (1980); ${ }^{\mathrm{f}}$ Zhang et al. (1997); ${ }^{\mathrm{g}}$ Iyoki et al. (1993); ${ }^{\mathrm{h}}$ Fabuss et al. (1969)

Table 4. Data set information for droplet-based measurements of binary aqueous electrolyte mixtures used to fit the AIOMFAC-VISC electrolyte model.

\begin{tabular}{lccccccc}
\hline Electrolyte & $N$ & $T_{\text {min }}$ & $T_{\text {max }}$ & $T_{\text {mean }}$ & $w_{\mathrm{w}, \text { min }}{ }^{\mathrm{a}}$ & $\log _{10}\left(\eta / \eta^{\circ}\right)_{\text {max }}^{\mathrm{b}}$ & $\log _{10}\left(\eta / \eta^{\circ}\right)_{\text {min }}^{\mathrm{b}}$ \\
\hline $\mathrm{Ca}\left(\mathrm{NO}_{3}\right)_{2}{ }^{\mathrm{c}}$ & 11 & 293.15 & 293.15 & 293.15 & 0.2685 & 1.977 & -1.485 \\
$\mathrm{Mg}\left(\mathrm{NO}_{3}\right)_{2}{ }^{\mathrm{c}}$ & 8 & 293.15 & 293.15 & 293.15 & 0.4854 & -1.403 & -2.402 \\
$\mathrm{NaNO}_{3}{ }^{\mathrm{d}}$ & 8 & 293.15 & 293.15 & 293.15 & 0.1261 & 0.540 & -2.558 \\
\hline
\end{tabular}

${ }^{\text {a }} w_{\mathrm{w}, \min }$ is the minimum mass fraction of water, which corresponds to the highest solute concentration. For droplet-based measurements, $w_{\mathrm{w}}$ is predicted by AIOMFAC.

b These columns show the maximum and minimum values for $\log _{10}\left(\eta / \eta^{\circ}\right)$ at $\mathrm{T}=295 \pm 5 \mathrm{~K}$, where $\eta^{\circ}$ denotes unit viscosity $(1 \mathrm{~Pa}$ s).

${ }^{c}$ Song et al. (2021) - Poke-flow and bead mobility; ${ }^{\mathrm{d}}$ Baldelli et al. (2016) - Holographic optical tweezers

\subsection{Generalizing AIOMFAC-VISC: three mixing models for organic-inorganic systems}

310 In the aerosol context, particle phases will frequently contain a mixture of water, organic compounds, and inorganic ions. Therefore, we introduce a second extension to AIOMFAC-VISC, enabling viscosity predictions for mixtures consisting of 
water and an arbitrary number of organic compounds and inorganic ions. We note that, to date, viscosity measurement data for organic-inorganic mixtures are scarce, limiting comparisons between model predictions and measurements and the quantitative evaluation of different mixing approaches. Given our two distinct models - the one introduced above for predicting viscosity in organic-free aqueous electrolyte solutions and the one for electrolyte-free aqueous organic mixtures (Gervasi et al., 2020) a coupled AIOMFAC-VISC mixing model for aqueous organic-inorganic mixtures can be designed in at least three ways.

In the following sections, we introduce three approaches for combining our aqueous electrolyte and aqueous organic viscosity models and discuss their differences in terms of physicochemical justification, implementation considerations and associated computational costs. Common to our approaches is the concept of describing the organic-inorganic system in each particle phase as a combination of two distinct subsystems: (1) an aqueous organic solution free of inorganic electrolytes, and (2) an organic-free aqueous electrolyte solution. Each subsystem may contain any number of components aside from water. The split into subsystems allows us to apply the appropriate organic- or electrolyte-specific viscosity model for each subsystem. For a given overall mixture composition, there is no obvious way, but several reasonable ways, by which the water content can be split into contributions to each subsystem; hence, different options emerge. Also, since water is the only common component present in the two subsystems, its modified properties (outlined in the following) can be considered to indirectly account for and mediate effects from interactions among ions and organics occurring in the actual (fully mixed) system.

\subsubsection{Electrolyte-aware water mixed with organics}

The first approach for computing the mixture viscosity, abbreviated as "aquelec", assumes that inorganic electrolytes dissolve exclusively in water as the predominant solvent for ions, which is typically a good approximation, especially under dilute aqueous solution conditions and/or in the absence of polar organic solvents. The key idea is to replace the pure component viscosity of water, which is used in the prediction of the mixture viscosity of the aqueous organic subsystem, by the viscosity predicted for the aqueous electrolyte subsystem. This electrolyte-aware "pseudo-pure" water property substitute is then applied together with the properties of the organic components in the organic model, which is based in part on combinatorial-activityweighted contributions of water and organics to determine mixture viscosity (Gervasi et al., 2020). In the aquelec mixing approach, the following steps are taken:

1. Adjust the ion molalities, which are by default defined by the molar ion amounts relative to $1 \mathrm{~kg}$ of water plus organics, $m_{i}=n_{i} /\left(W_{\mathrm{w}}+\sum W_{\text {org }}\right)$, to be instead redefined relative to $1 \mathrm{~kg}$ of pure water as solvent, where $m_{i, \text { aquelec }}=n_{i} / W_{\mathrm{w}}$. In these expressions, $n_{i}$ is the molar amount of ion $i$, and $W_{\text {org }}$ and $W_{\mathrm{w}}$ are the masses of organic and water components, respectively, present in the total mixture. This can be expressed using a conversion factor, $\lambda$, as follows:

$$
\begin{aligned}
& m_{i, \text { aquelec }}=\lambda m_{i}, \\
& \lambda=W_{\mathrm{w}} /\left(W_{\mathrm{w}}+\sum W_{\text {org }}\right)=w_{\mathrm{w}} /\left(w_{\mathrm{w}}+\sum w_{\text {org }}\right) .
\end{aligned}
$$

2. Using $m_{i, \text { aquelec }}$, calculate ion activities with Eq. (9) and ionic strength with Eq. (15). 
3. Redefine the ionic mole fractions relative to the organic-free aqueous electrolyte subsystem (subsystem 2). The full system ionic mole fractions, $x_{i}=n_{i} /\left(n_{w}+\sum n_{\text {org }}+\sum n_{i}\right)$, are replaced by the new "organic-free" ionic mole fractions, $x_{i, \text { aquelec }}=x_{i} /\left(x_{\mathrm{w}}+\sum x_{i^{\prime}}\right)$. Here, we introduce prime notation, e.g. $i^{\prime}$, to contrast the specific ion $i$ with the index over which all ion molar amounts or mole fractions are summed.

4. Run the electrolyte model to calculate the viscosity of the aqueous electrolyte subsystem, ignoring organics.

5. Replace the pure-component viscosity of water in subsystem 1 with that of the aqueous electrolyte subsystem (electrolyteaware water).

6. Set the mole fractions of ions to zero to avoid double-counting their effects and renormalize the mole fractions of water and organics for subsystem 1 , so they become $x_{w, \text { aquelec }}=x_{\mathrm{w}} /\left(x_{\mathrm{w}}+\sum x_{\text {org }}\right)$ and $x_{\text {org }, \text { aquelec }}=x_{\text {org }} /\left(x_{\mathrm{w}}+\sum x_{\text {org }}{ }^{\prime}\right)$.

7. Run the organic model (Gervasi et al., 2020) for the established mixture of electrolyte-aware water and the organic components to compute the viscosity of the organic-inorganic mixture as a whole.

\subsubsection{Organics-aware water mixed with ions}

As opposed to aquelec, another option, "aquorg", assumes that all water mixes with organic components to create an "organicsaware" water component that will replace pure water as the solvent of ions in the organic-inorganic mixture. Unlike aquelec, which first computes the interactions between ions and pure water, aquorg prioritizes the calculation for aqueous organic mixture viscosity. This mixing model is similar to aquelec, but the steps proceed in a different order, as follows:

1. Run the organic model (Gervasi et al., 2020) to calculate the viscosity for the aqueous organic subsystem, ignoring ions.

2. Replace the pure-component viscosity property of water in subsystem 2 with that of the aqueous organic subsystem (organics-aware water).

3. Add the mole fraction values of all organics to the mole fraction of water, and set the mole fractions of all organics to zero. Thus, the sum of moles of organics + moles of water is represented as moles of organics-aware water.

4. Run the electrolyte model for the mixture of organics-aware water and the inorganic ions to calculate viscosity of the organic-inorganic mixture.

Note that for the aquorg mixing mode, it is not necessary to modify the ion molalities because they are computed relative to $1 \mathrm{~kg}$ of organics-aware water, which for this purpose is equivalent to the molality definition based on mass of water + organics in the denominator (as in the original mixture). 


\subsubsection{Splitting water content between organic and inorganic subsystems with a Zdanovskii-Stokes-Robinson mixing rule}

The third mixing model is a Zdanovskii-Stokes-Robinson (ZSR) type mixing rule that preserves the organic-to-inorganic dry mass ratio (OIR). The ZSR mixing rule has been successfully used in many applications for the estimation of physical properties of a ternary mixture based on additive contributions from binary subsystems evaluated at the same water activity (i.e. RH under bulk equilibrium conditions) (Zdanovskii, 1936, 1948; Stokes and Robinson, 1966).

Unlike the other two mixing models described above, which only require a single call of the AIOMFAC program (for the computation of activity coefficients), the ZSR-style approach requires an iterative numerical solution: multiple runs are needed to pinpoint the mass fraction of water of the aqueous electrolyte and aqueous organic subsystems such that they yield the same water activity as that determined for the full mixture. As water activity is an output of an AIOMFAC calculation, this requires solving a non-linear equation in one unknown (mass fraction of water) for each subsystem.

Our ZSR-style mixing rule first calculates the RH of the full organic-inorganic system. Next, we split the full system into a salt-free aqueous organic subsystem (subsystem 1) and an organic-free aqueous electrolyte subsystem (subsystem 2). A modified version of Powell's hybrid method from the Fortran MINPACK library is used to calculate the water content and viscosity for the two subsystems at the target RH (Moré et al., 1980, 1984). Finally, the organic-inorganic mixture viscosity is estimated using a weighted arithmetic mean of the logarithms of subsystem viscosities, which is equivalent to a weighted geometric mean of the non-log subsystem viscosities. The expression for the mixing rule, previously described in Song et al. (2021), is

$\ln \left(\eta / \eta^{\circ}\right)=f_{1} \ln \left(\eta_{1} / \eta^{\circ}\right)+f_{2} \ln \left(\eta_{2} / \eta^{\circ}\right)$,

where $f_{1}$ and $f_{2}$ are the relative mass contributions from subsystem 1 and 2 , respectively. $\eta^{\circ}$ denotes unit viscosity ( 1 Pas). Expressions for $f_{1}$ and $f_{2}$ must ensure that the given OIR is preserved. Consider the mass $W$ of the full system,

$W=W_{\text {org }}+W_{e l}+W_{\mathrm{w}}$,

where org, el, and w denote organic, electrolyte (salt), and water components, respectively. Subsystem 1 contains all of the organic mass and subsystem 2 contains all of the salt mass; the water content can be split in a way that preserves OIR. By defining the mass of the subsystems as

$W_{1}=W_{\text {org }, 1}+W_{\mathrm{w}, 1}$,

$W_{2}=W_{e l, 2}+W_{\mathrm{w}, 2}$,

$W_{e l}=W_{e l, 2}$,

$W_{\text {org }}=W_{\text {org }, 1}$,

OIR can be defined as

$\mathrm{OIR}=\frac{W_{\text {org }}}{W_{e l}}=\frac{W_{\text {org }, 1}}{W_{e l, 2}}=\frac{w_{\text {org }, 1} W_{1}}{w_{e l, 2} W_{2}}$, 
where $w_{o r g, 1}, w_{e l, 2}$ are the mass fractions of the organic in subsystem 1 and salt in subsystem 2 , respectively. The relative mass contributions are defined as

$f_{1}=\frac{W_{1}}{W_{1}+W_{2}}$,

$f_{2}=1-f_{1}$.

Combining (29) and (28), we find that

$f_{1}=\frac{\mathrm{OIR} \times w_{e l, 2}}{w_{\text {org }, 1}+\mathrm{OIR} \times w_{e l, 2}}$.

Note that $f_{1}$ and $f_{2}$ are not constant for constant OIR and must be recomputed at every RH step. In dynamic simulations, it is expected that ZSR mixing will be computationally expensive due to the multiple calls to AIOMFAC and the iterative approach.

\subsubsection{Advantages and disadvantages of the different mixing models}

The perfect mixing model for viscosity will be physically justifiable, efficient, and accurate. The ZSR mixing rule to determine water content is built on established thermodynamic arguments, but its implementation is computationally more expensive than the other two mixing models. The "aquelec" and "aquorg" mixing models are about equally fast because neither requires an iterative approach, but the aquelec approach seems the more reasonable choice in terms of physicochemical justification. The primary assumption of the aquelec mixing model is that ions are likely to dissolve preferentially in water. By contrast, the aquorg mixing model implicitly treats organic components similar to water in terms of acting as solvent mass for the calculations in subsystem 2, which is not always a good assumption. In terms of accuracy, recently, the ZSR mixing rule has been shown to produce reasonable predictions of viscosity within an order of magnitude of measurements (Song et al., 2021). A ZSR mixing rule likely suffices for non-reactive/non-interacting mixtures that exist as Newtonian fluids over a wide RH range. Some aqueous electrolytes and organic-inorganic mixtures, particularly those containing divalent cations, have been observed to undergo gel transitions at low RH (Cai et al., 2015; Richards et al., 2020b). Such gel phase transitions are not explicitly accounted for by AIOMFAC-VISC, and this may pose a challenge for the ZSR mixing rule. Predictions of organic-inorganic mixture viscosity with the three different approaches are compared in Sect. 4.7.

\subsubsection{Activity coefficient calculations}

Concurrently with the viscosity calculations, a full calculation is also carried out to determine the activity coefficients of all components/ions in the mixed organic-inorganic solution, as is also done in the absence of viscosity calculations with AIOMFAC. This is necessary because the activity coefficients of the components/ions computed for the subsystems will differ from those computed for the full system. 


\section{Results and Discussion}

Following a simultaneous fit of the AIOMFAC-VISC coefficients and implementation of the model in the AIOMFAC program, we found that AIOMFAC-VISC attained excellent agreement with bulk and droplet-based measurements and smooth extrapolations to low water contents for all 43 aqueous electrolyte systems. In this section, the values of the model parameters are reported and model design considerations are discussed first. Next, results are shown and discussed for binary, ternary, and quaternary aqueous electrolyte solutions, demonstrating the predictive capacity of the AIOMFAC-VISC aqueous electrolyte model. Finally, AIOMFAC-VISC predictions are shown for several aqueous inorganic and organic-inorganic mixtures for which recent aerosol techniques have been used to measure viscosity at target RH. The vast range of viscosities observed in nature, spanning more than 15 orders of magnitude, as well as the observed change of viscosity with composition, e.g. aerosol water content, or temperature, makes the use of a logarithmic viscosity scale useful; hence the frequent use of $\log _{10}\left(\eta / \eta^{\circ}\right)$ in this work.

\subsection{Fitting AIOMFAC-VISC for aqueous electrolyte solutions}

As discussed in Sect. 3.2, our method involved defining an objective function to fit the model. Our objective function is defined for each data set and takes the form

$f_{\text {obj }}=\sqrt{\frac{1}{N} \sum_{\iota=1}^{N}\left[\ln \left(\frac{\eta_{\text {calc }, \iota}+\sigma \cdot \eta_{\exp , \iota}}{\eta_{\exp , \iota}+\sigma \cdot \eta_{\exp , \iota}}\right)\right]^{2}}$,

where $\iota$ in the data point index, $N$ is the number of data points, and $\sigma$ is an uncertainty threshold. Summing the $f_{\text {obj }}$ values over all data sets and dividing by the sum gives the relative error contribution for each data set. $\mathrm{Ca}\left(\mathrm{NO}_{3}\right)_{2}, \mathrm{LiCl}$, and $\mathrm{CaCl} \mathrm{Cl}_{2}$ contribute the largest shares of error, as shown in Fig. 1. Our objective function includes a $2 \%$ uncertainty term $(\sigma=0.02)$ to characterize an approximate viscosity measurement error. However, it does not include additional consideration for the asymmetric distribution of measurements across different ranges in concentrations or temperature at which the measurements were collected, which may affect the distribution of the objective function value.

Through trial and error, we arrived at a framework that includes two coefficients per ion, one per cation-anion pair, and one volume correction term that is used for all model calculations. With the 43 aqueous electrolyte systems included in our fit, 58 unique coefficients were identified, describing 13 ions and 31 cation-anion interactions. Several $c_{c, a}$ coefficients were not covered by the measured systems but can still occur in AIOMFAC-VISC predictions; therefore, coefficients from similar cation-anion pairs were substituted in these cases, serving as approximations, e.g., $c_{\mathrm{Mg}^{2+}, \mathrm{Br}^{-}}=c_{\mathrm{Mg}^{2+}, \mathrm{Cl}^{-}}$. All values of these coefficients are included in Tables 5 and 6, and replacements are noted in Table S3. The fitted $c_{v}$ value is 1.558635 .

\subsection{Model design considerations}

How many parameters are needed to accurately and meaningfully model the viscosity of a binary aqueous electrolyte solution? The answer to this question is not so simple, as some parameters are defined for the entire model, whereas others are soluteor ion-specific. The model by Lencka et al. (1998) extends the Jones-Dole framework by including ionic $B$-coefficients and 
introducing a third term for species-species interaction that is proportional to the square of molar ionic strength. It requires three parameters: two ionic $B$-coefficients and one binary interaction parameter. As in the Jones-Dole equation, however, the $B$-coefficients are temperature-dependent and some aqueous electrolyte solutions require extra parameters for the speciesspecies interaction term. By contrast, the Laliberté (2007) model uses six coefficients per electrolyte. Temperature dependence is embedded in their expression for solute viscosity, and their use of six coefficients per electrolyte is able to correlate viscosity over a broad concentration range (with limited extrapolation beyond the concentration and temperature range of available measurement data), meaning that the full flexibility of his model is contained in a single equation.

We argue that AIOMFAC-VISC is more predictive and versatile than Laliberté's model because AIOMFAC-VISC's singleion coefficients are simultaneously fitted with data from multiple aqueous electrolyte systems and can be used to estimate viscosity in binary and multi-electrolyte systems for which no laboratory viscosity measurements exist. Furthermore, Laliberté's mixing model, a mass-fraction-weighted mixing rule, requires knowledge of the solute concentration in terms of associated electrolyte units. Atmospheric aerosols often include multiple dissociated cations and anions, as is the case with aerosolized seawater (Fabuss et al., 1969; Prather et al., 2013). In the Laliberté model, predicting the viscosity of multi-ion solutions introduces ambiguity because the ions would need to be mapped into electrolyte units. For example, an aqueous mixture of $\mathrm{KBr}$ and $\mathrm{NaCl}$ and an aqueous mixture of $\mathrm{KCl}$ and $\mathrm{NaBr}$ have different calculated viscosities according to the Laliberté model, even though the ionic concentrations are identical. AIOMFAC-VISC can sidestep this problem of electrolyte ambiguity with its unique design. A further aspect of the use of single-ion contributions to viscosity, via Eq. (13), is the dependence on predicted single-ion activities in this expression, allowing the resulting $\Delta g_{i}^{*}$ term to indirectly account for non-ideal mixing effects. This means that effects of specific counter-ions on a particular ion in the solution, at otherwise the same solute molality, are considered. Therefore, while the single-ion coefficients $\left(c_{0, i}\right.$ and $\left.c_{1, i}\right)$ are the same for ion $i$ in any mixture, the interaction effects of the reference solvent and of other ions present are at least partially accounted for.

\subsection{Comparison of AIOMFAC-VISC and the Laliberté model for aqueous electrolyte systems}

480 Due to the substantial overlap in fitted data sets, we use the Laliberte model as a benchmark for AIOMFAC-VISC, both with respect to its closeness of fit to bulk viscosity measurements and its extrapolative behavior. We fitted AIOMFAC-VISC to available bulk viscosity measurements, resulting in excellent agreement for all data sets, although that is less apparent when compared with the Laliberté model. For example, in Fig. 1, we see that in panels (b)-(d) and for all systems, AIOMFACVISC's error magnitude is greater than that of the Laliberté model. This is expected, because the Laliberte model is fitted to aqueous electrolyte solutions (with six specific, independent parameters for each system) as opposed to AIOMFAC-VISC, which includes ion-specific coefficients shared among many electrolyte systems. The left-most panel displays mean bias error (MBE) for the binary systems defined in Table 2. MBE is defined as

$\mathrm{MBE}=\frac{1}{N} \sum_{\iota=1}^{N}\left(\log _{10}\left[\eta_{\text {calc }, \iota} / \eta^{\circ}\right]-\log _{10}\left[\eta_{\exp , \iota} / \eta^{\circ}\right]\right)$,

where $N$ is the number of points in each data set, $\eta_{\text {calc }, \iota}$ is the calculated viscosity value of either AIOMFAC-VISC or the Laliberté model, and $\eta_{\exp , \iota}$ is the viscosity value reported in the measurements at point $\iota$. Overall, AIOMFAC-VISC does 
Table 5. AIOMFAC-VISC ion coefficients, $c_{0, i}$ and $c_{1, i}{ }^{\text {a }}$

\begin{tabular}{cll}
\hline Ion & \multicolumn{1}{c}{$c_{0}$} & \multicolumn{1}{c}{$c_{1}$} \\
\hline $\mathrm{H}^{+}$ & $1.010392 \times 10^{-11}$ & 4.984977 \\
$\mathrm{Li}^{+}$ & $2.859452 \times 10^{-2}$ & 5.813186 \\
$\mathrm{~K}^{+}$ & $1.338914 \times 10^{-1}$ & $7.276922 \times 10^{-1}$ \\
$\mathrm{Na}^{+}$ & $1.997467 \times 10^{-1}$ & 5.206617 \\
$\mathrm{Ca}^{2+}$ & 1.739591 & $1.523731 \times 10^{1}$ \\
$\mathrm{NH}_{4}^{+}$ & $1.141345 \times 10^{-1}$ & 1.987456 \\
$\mathrm{Mg}^{2+}$ & $1.010392 \times 10^{-11}$ & $1.455225 \times 10^{1}$ \\
$\mathrm{Cl}^{-}$ & $1.010392 \times 10^{-11}$ & 6.276431 \\
$\mathrm{Br}^{-}$ & $2.061758 \times 10^{-1}$ & 3.398860 \\
$\mathrm{NO}_{3}^{-}$ & $7.306100 \times 10^{-1}$ & 4.473847 \\
$\mathrm{SO}_{4}^{2-}$ & $1.010392 \times 10^{-11}$ & $1.891437 \times 10^{1}$ \\
$\mathrm{HSO}_{4}^{-}$ & $3.582738 \times 10^{-1}$ & 5.200661 \\
$\mathrm{I}^{-}$ & $3.335912 \times 10^{-2}$ & 2.476017 \\
\hline
\end{tabular}

${ }^{\mathrm{a}}$ The number of digits listed reflects approximately the precision used in the model code; it does not imply that all digits are significant figures.

not exhibit systematic bias, with negative bias for 18 data sets and positive bias for 8 data sets. The magnitudes of MBE are generally larger for AIOMFAC-VISC than for the Laliberté model, which again is expected. Two systems stand out, however: $\mathrm{NaNO}_{3}$ and $\mathrm{Ca}\left(\mathrm{NO}_{3}\right)_{2}$, both of which show positive bias. These two systems include some of the highest viscosity values among the available measurements, which is a factor in their large contributions to the overall objective function error. $\mathrm{NaNO}_{3}$ and $\mathrm{Ca}\left(\mathrm{NO}_{3}\right)_{2}$ also include both bulk and droplet-based measurements, and these data do not agree at low water content, leading to larger fit residuals for these systems. It is also worth noting that the Laliberté model has its largest value of MBE for $\mathrm{Ca}\left(\mathrm{NO}_{3}\right)_{2}$, suggesting that this system is difficult to model, even when using more adjustable parameters. Figs. $1 \mathrm{~b}$,c show mean absolute error (MAE), which is defined as

$\mathrm{MAE}=\frac{1}{N} \sum_{\iota=1}^{N}\left|\log _{10}\left[\eta_{\mathrm{calc}, \iota} / \eta^{\circ}\right]-\log _{10}\left[\eta_{\exp , \iota} / \eta^{\circ}\right]\right|$,

and root mean square error (RMSE), which is defined as

$\operatorname{RMSE}=\sqrt{\frac{1}{N} \sum_{\iota=1}^{N}\left(\log _{10}\left[\eta_{\text {calc }, \iota} / \eta^{\circ}\right]-\log _{10}\left[\eta_{\exp , \iota} / \eta^{\circ}\right]\right)^{2} .}$

The most significant deviations from the measurements are for $\mathrm{Ca}\left(\mathrm{NO}_{3}\right)_{2}, \mathrm{NaNO}_{3}, \mathrm{LiCl}$, and $\mathrm{CaCl}_{2}$. The values of the root mean square error and the custom objective function, Eq. (32), are presented in panels (c) and (d) of Fig. 1, and reinforce the same result. 
Table 6. AIOMFAC-VISC cation-anion pair coefficient, $c_{c, a} \cdot{ }^{\mathrm{a}, \mathrm{b}}$

\begin{tabular}{|c|c|c|c|c|c|c|c|}
\hline Cation & Anion & $c_{c, a}$ & & Cation & Anion & $c_{c, a}$ & \\
\hline $\mathrm{H}^{+}$ & $\mathrm{Cl}^{-}$ & $5.258463 \times 10^{-1}$ & & $\mathrm{H}^{+}$ & $\mathrm{SO}_{4}^{2-}$ & 3.408676 & \\
\hline $\mathrm{Li}^{+}$ & $\mathrm{Cl}^{-}$ & 1.905466 & & $\mathrm{Li}^{+}$ & $\mathrm{SO}_{4}^{2-}$ & 6.020485 & \\
\hline $\mathrm{K}^{+}$ & $\mathrm{Cl}^{-}$ & $6.687233 \times 10^{-1}$ & & $\mathrm{~K}^{+}$ & $\mathrm{SO}_{4}^{2-}$ & 3.673562 & \\
\hline $\mathrm{Na}^{+}$ & $\mathrm{Cl}^{-}$ & $8.801056 \times 10^{-1}$ & & $\mathrm{Na}^{+}$ & $\mathrm{SO}_{4}^{2-}$ & 4.069814 & \\
\hline $\mathrm{Ca}^{2+}$ & $\mathrm{Cl}^{-}$ & 1.171834 & & $\mathrm{Ca}^{2+}$ & $\mathrm{SO}_{4}^{2-}$ & 8.288825 & * \\
\hline $\mathrm{NH}_{4}^{+}$ & $\mathrm{Cl}^{-}$ & $1.010392 \times 10^{-11}$ & & $\mathrm{NH}_{4}^{+}$ & $\mathrm{SO}_{4}^{2-}$ & $9.750427 \times 10^{-1}$ & \\
\hline $\mathrm{Mg}^{2+}$ & $\mathrm{Cl}^{-}$ & 5.235014 & & $\mathrm{Mg}^{2+}$ & $\mathrm{SO}_{4}^{2-}$ & 8.288825 & \\
\hline $\mathrm{H}^{+}$ & $\mathrm{Br}^{-}$ & 1.617729 & & $\mathrm{H}^{+}$ & $\mathrm{HSO}_{4}^{-}$ & $2.044069 \times 10^{-1}$ & \\
\hline $\mathrm{Li}^{+}$ & $\mathrm{Br}^{-}$ & 1.647985 & & $\mathrm{Li}^{+}$ & $\mathrm{HSO}_{4}^{-}$ & 2.409278 & $*$ \\
\hline $\mathrm{K}^{+}$ & $\mathrm{Br}^{-}$ & 1.587642 & & $\mathrm{~K}^{+}$ & $\mathrm{HSO}_{4}^{-}$ & 2.409278 & * \\
\hline $\mathrm{Na}^{+}$ & $\mathrm{Br}^{-}$ & 1.673620 & & $\mathrm{Na}^{+}$ & $\mathrm{HSO}_{4}^{-}$ & 2.409278 & \\
\hline $\mathrm{Ca}^{2+}$ & $\mathrm{Br}^{-}$ & 1.171834 & * & $\mathrm{Ca}^{2+}$ & $\mathrm{HSO}_{4}^{-}$ & 2.409278 & * \\
\hline $\mathrm{NH}_{4}^{+}$ & $\mathrm{Br}^{-}$ & $1.185873 \times 10^{-1}$ & & $\mathrm{NH}_{4}^{+}$ & $\mathrm{HSO}_{4}^{-}$ & 2.409278 & * \\
\hline $\mathrm{Mg}^{2+}$ & $\mathrm{Br}^{-}$ & 5.235014 & * & $\mathrm{Mg}^{2+}$ & $\mathrm{HSO}_{4}^{-}$ & 2.409278 & $*$ \\
\hline $\mathrm{H}^{+}$ & $\mathrm{NO}_{3}^{-}$ & $4.881596 \times 10^{-1}$ & & $\mathrm{H}^{+}$ & $\mathrm{I}^{-}$ & 1.541868 & \\
\hline $\mathrm{Li}^{+}$ & $\mathrm{NO}_{3}^{-}$ & 1.010443 & & $\mathrm{Li}^{+}$ & $\mathrm{I}^{-}$ & 2.609099 & \\
\hline $\mathrm{K}^{+}$ & $\mathrm{NO}_{3}^{-}$ & 1.657611 & & $\mathrm{~K}^{+}$ & $\mathrm{I}^{-}$ & 2.073405 & \\
\hline $\mathrm{Na}^{+}$ & $\mathrm{NO}_{3}^{-}$ & 2.011382 & & $\mathrm{Na}^{+}$ & $\mathrm{I}^{-}$ & 2.410199 & \\
\hline $\mathrm{Ca}^{2+}$ & $\mathrm{NO}_{3}^{-}$ & 5.169580 & & $\mathrm{Ca}^{2+}$ & $\mathrm{I}^{-}$ & 1.171834 & * \\
\hline $\mathrm{NH}_{4}^{+}$ & $\mathrm{NO}_{3}^{-}$ & $6.112194 \times 10^{-1}$ & & $\mathrm{NH}_{4}^{+}$ & $\mathrm{I}^{-}$ & $1.010392 \times 10^{-11}$ & * \\
\hline $\mathrm{Mg}^{2+}$ & $\mathrm{NO}_{3}^{-}$ & 4.406500 & & $\mathrm{Mg}^{2+}$ & $\mathrm{I}^{-}$ & 5.235014 & * \\
\hline
\end{tabular}

${ }^{a}$ The number of digits listed reflects approximately the precision used in the model code; it does not imply that all digits are significant figures.

$\mathrm{b} *$ denotes cation-anion pairs for which no measurements were available. In these cases, the fit parameter of a similar pair is substituted, e.g., $\mathrm{Ca}^{2+} \mathrm{Br}^{-}$uses the same value as $\mathrm{Ca}^{2+} \mathrm{Cl}^{-}$. See Table $\mathrm{S} 3$ for full list of substitutions made. 

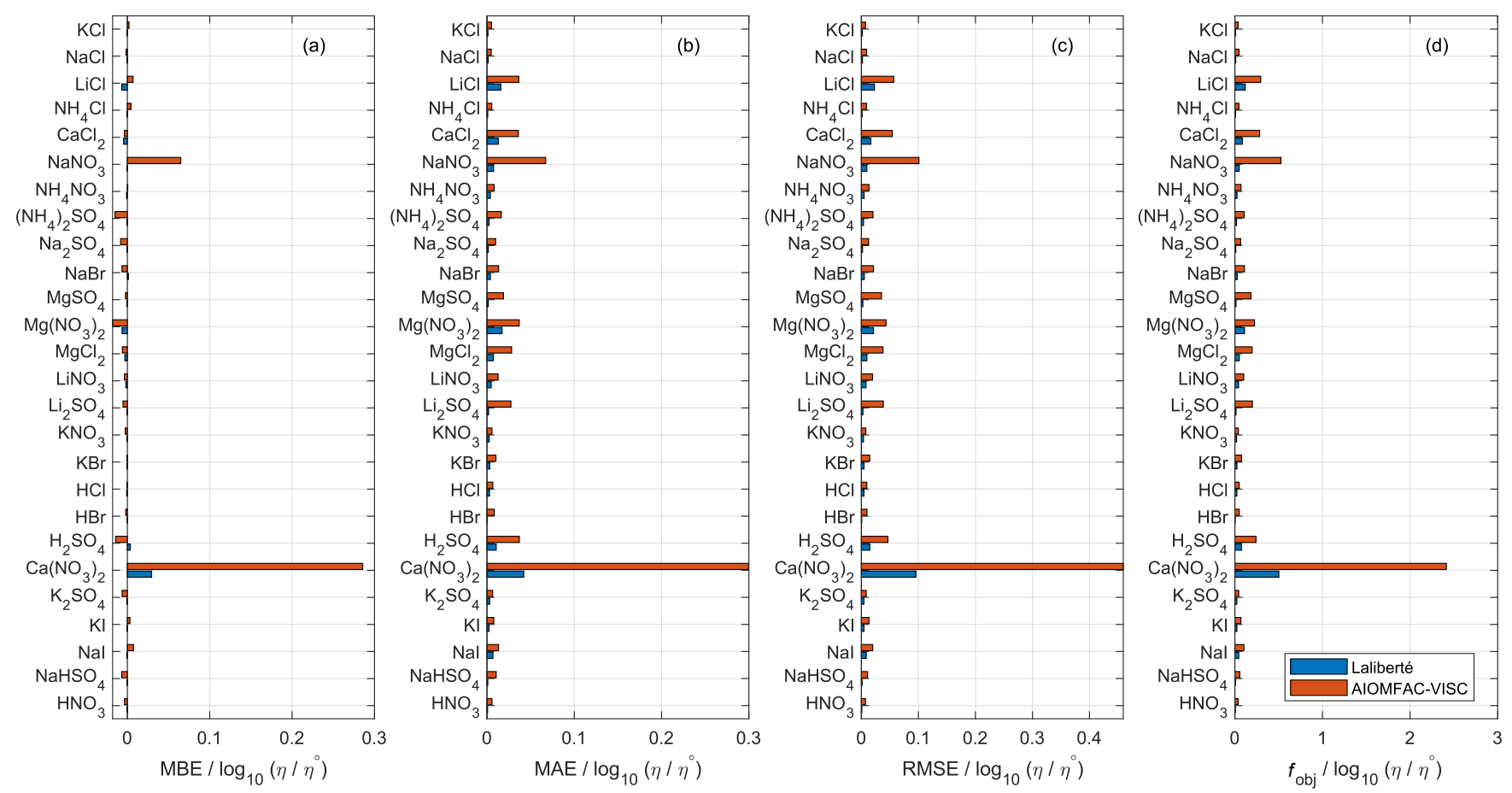

Figure 1. Comparison of AIOMFAC-VISC and the Laliberté model in terms of (a) mean bias error, (b) mean absolute error, (c) root mean square error, and (d) custom objective function value used to fit AIOMFAC-VISC. See Table 2 for information on number of data points, the ranges of temperature, concentration, and viscosity for each data set. $\eta^{\circ}$ denotes unit viscosity (1 Pas).

In Fig. 2, the panels are zoomed in individually to show how AIOMFAC-VISC and the Laliberté model align with the bulk viscosity measurements over the covered concentration and viscosity ranges. $\mathrm{KCl}$ (Fig. 2a) and $\mathrm{NH}_{4} \mathrm{Cl}$ (Fig. 2d) show local minima in their measured viscosity curves, a characteristic of structure-breaking electrolytes that is better captured by the Laliberté model for these systems. In these panels, as well as for $\mathrm{NaCl}$ (Fig. 2b), it is evident that the Laliberté model has a closer fit with the measurements. Note that the panels for $\mathrm{KCl}$ and $\mathrm{NH}_{4} \mathrm{Cl}$ have extremely narrow vertical axes ranges, effectively only showing viscosities close to that of pure water. Some panels, by contrast, span more than one order of magnitude, with AIOMFAC-VISC agreeing well with the highest viscosity measurements. We note that if AIOMFAC-VISC is fitted only to data for an individual binary electrolyte solution, such as that for $\mathrm{NH}_{4} \mathrm{Cl}$ shown in Fig. 2d, the model is capable of reproducing the local minimum in measured viscosity. This indicates that the shown deviations are a result of the simultaneous fit of the model to many data sets covering a wider range in concentrations and viscosities.

\section{4.4 Closeness of fit to bulk viscosity measurements for ternary and quaternary aqueous electrolyte mixtures}

Viscosity measurements for mixtures of water and more than one electrolyte are less common than those of binary aqueous solutions, but they better demonstrate AIOMFAC-VISC's predictive capacity. The data sets in Table 3 were used to fit 

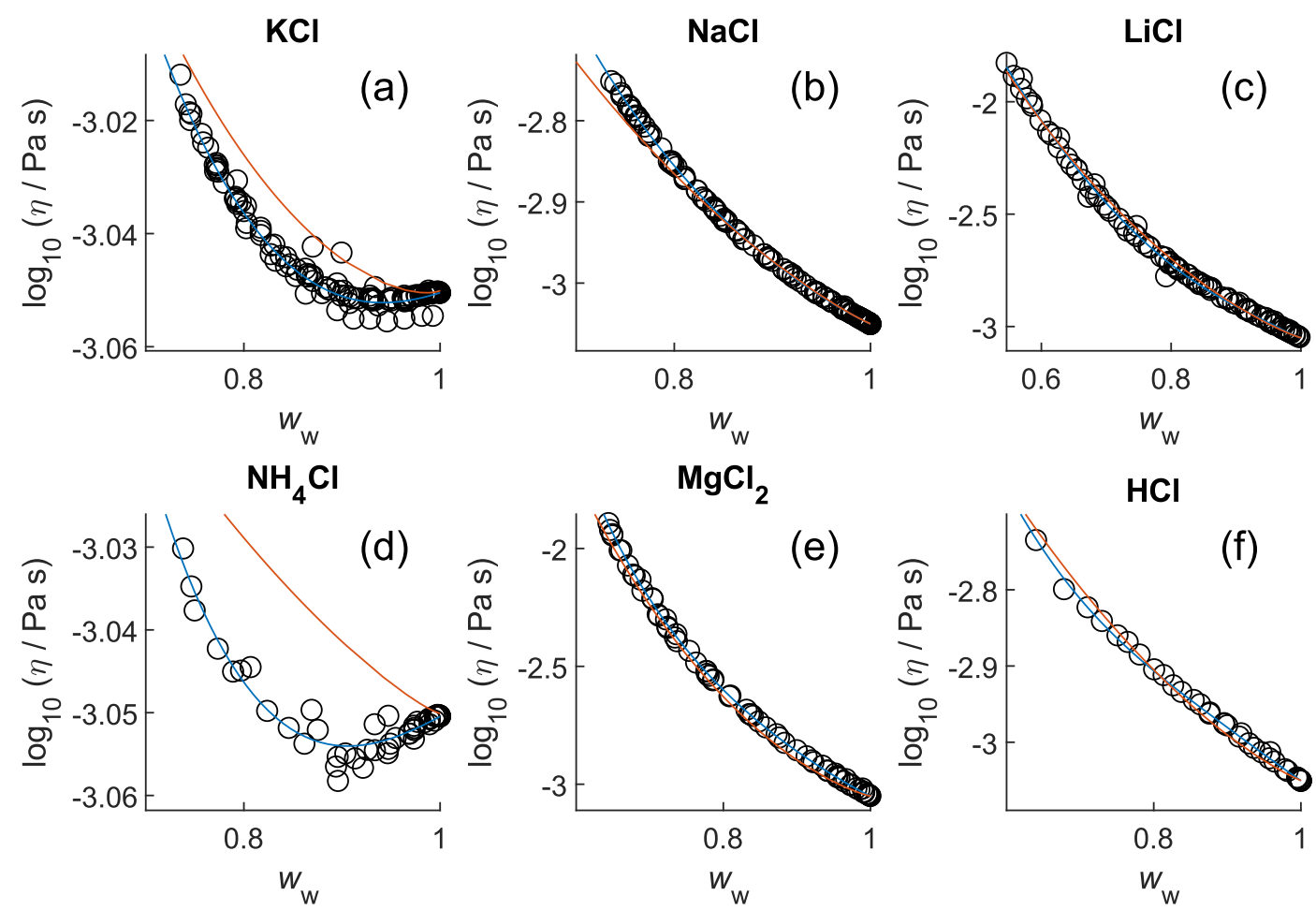

$\mathrm{MgCl}_{2}$

$\mathrm{HCl}$
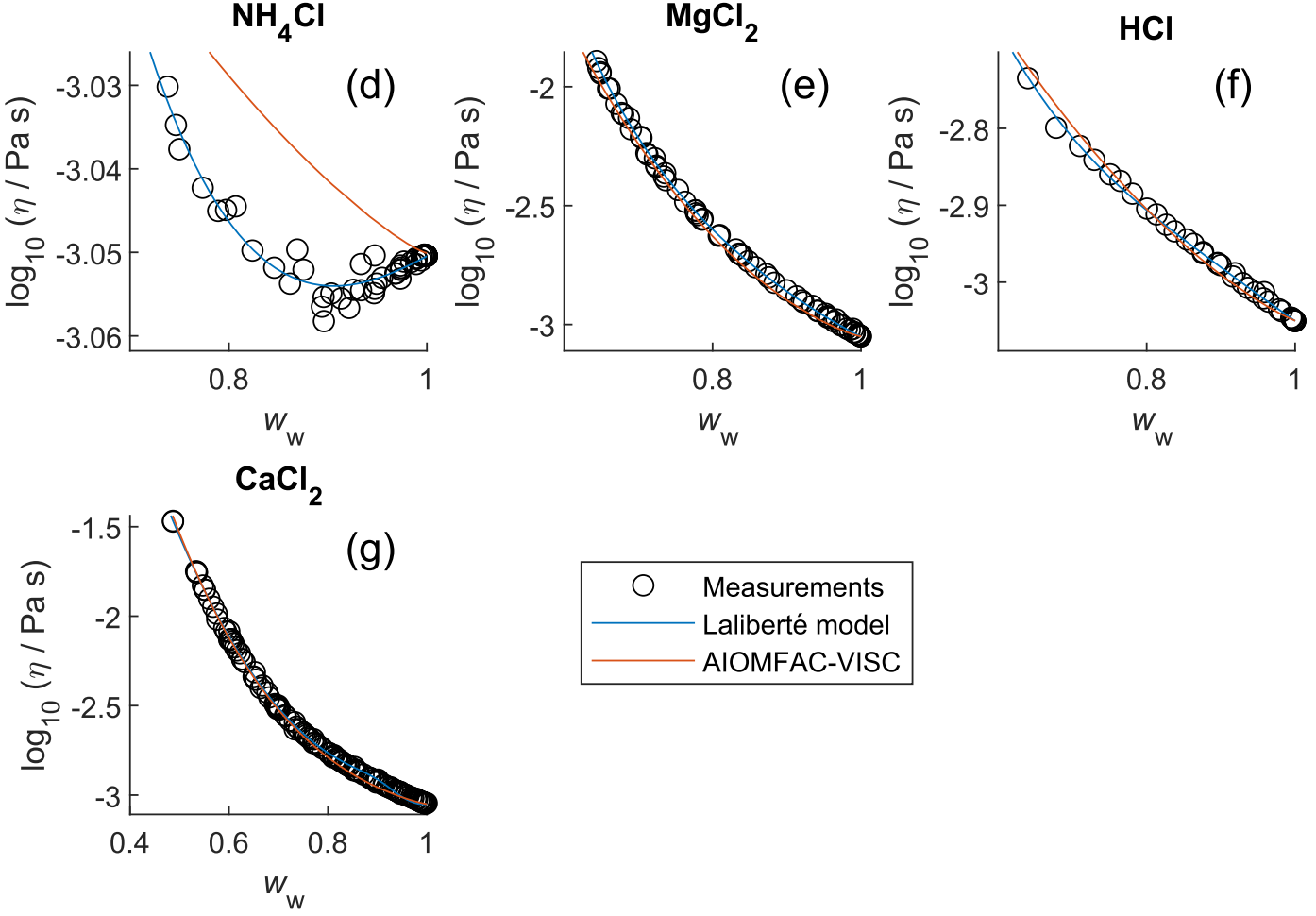

Figure 2. Comparison of closeness of fit for aqueous chloride salts/acids at $298 \mathrm{~K}$. Zooms are adjusted in each panel to best fit the measurement ranges. See Fig. 4 for model extrapolations throughout the full concentration range and Table 2 for information on the measurement data. 
(a)
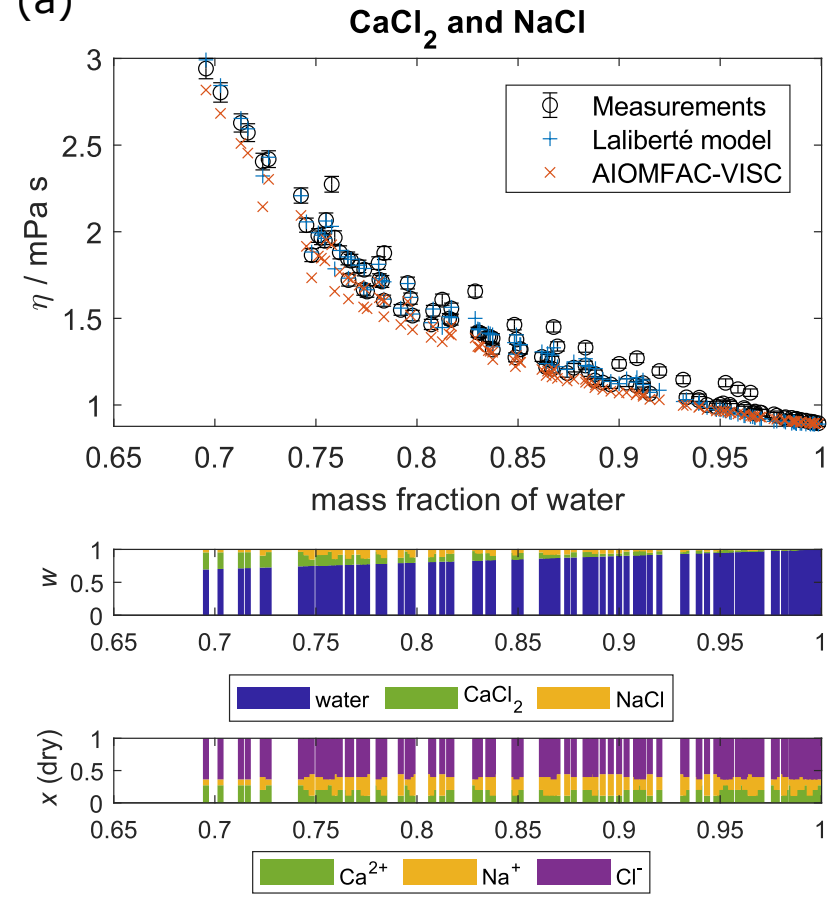

(b)
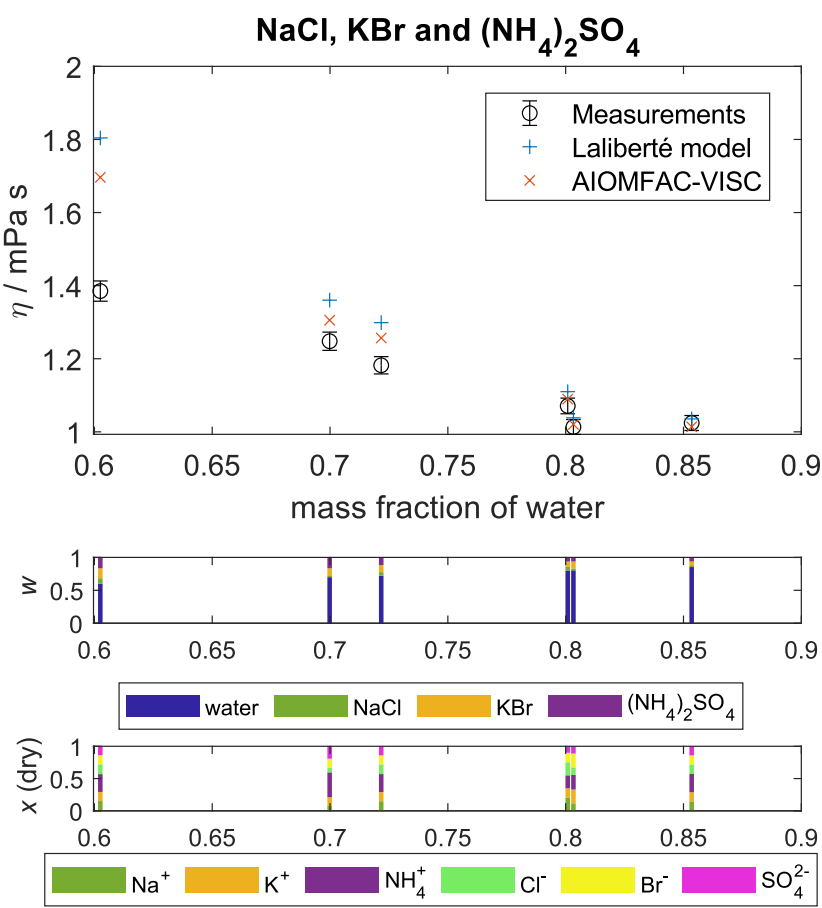

Figure 3. Comparison of AIOMFAC-VISC predictions and Laliberté model results with measured data points for aqueous mixtures of more than one electrolyte: (a) $\mathrm{CaCl}_{2}$ and $\mathrm{NaCl}$ and (b) $\mathrm{NaCl}, \mathrm{KBr}$, and $\left(\mathrm{NH}_{4}\right)_{2} \mathrm{SO}_{4}$. Middle panel bar graphs show the mass fractions ( $w$ ) with respect to non-dissociated electrolytes and lower bar graphs show the ion mole fractions with water excluded, $x$ (dry). $2 \%$ vertical error bars are included to represent viscosity measurement error.

AIOMFAC-VISC, but were not fitted by the Laliberté model. Therefore, we effectively compare AIOMFAC-VISC's fit for these multi-ion solutions to the Laliberté mixing model, the latter being a simple mass-fraction-weighted mixing rule. As these measurements are on the same order of magnitude as the viscosity of pure water, we change the units on the vertical axis to $\mathrm{mPas}$, and include $2 \%$ error bars.

Figure 3 shows AIOMFAC-VISC predictions alongside measurements and Laliberté-calculated values for two aqueous multi-ion solutions. As with the binary solution results, AIOMFAC-VISC and the Laliberté model agree closely at high mass fraction of water and diverge as the solute concentration increases. In Fig. 3a, there is close agreement between the two models and the measurements. This behavior is expected due to the strong model-measurement agreement of binary $\mathrm{NaCl}$ and binary $\mathrm{CaCl}_{2}$. Considering the much larger viscosity scale that is typical for atmospheric aerosol cases, this level of agreement with the measurements is very encouraging. For the ternary aqueous electrolyte mixture $\mathrm{H}_{2} \mathrm{O}+\mathrm{CaCl}_{2}+\mathrm{NaCl}$ in Fig 3a, the Laliberté model requires 12 parameters, or six for each electrolyte. AIOMFAC-VISC, by contrast, includes two coefficients for each individual ion, reducing the number needed in the case of common ions, in this case $\mathrm{Cl}^{-}$. For this example, AIOMFAC-VISC depends on only 9 of the fitted coefficients, namely 2 for $\mathrm{Ca}^{2+}, 2$ for $\mathrm{Na}^{+}, 2$ for $\mathrm{Cl}^{-}, 1$ for the 
first cation-anion pair, $\mathrm{Ca}^{2+}-\mathrm{Cl}^{-}, 1$ for the second cation-anion pair, $\mathrm{Na}^{+}-\mathrm{Cl}^{-}$, plus 1 for the volume correction term. In Fig 3b, the number of data points is much smaller, but AIOMFAC-VISC outperforms the Laliberté model for 5 out of 6 points. This is likely due to AIOMFAC-VISC's more comprehensive treatment for dissolved ions and cation-anion pairs and because we used these data during the simultaneous fit of the aqueous electrolyte model. While the Laliberté model characterizes three electrolytes and their mixing, AIOMFAC-VISC accounts for nine potential cation-anion pairs and weights their contributions in a stoichiometrically consistent way. Additional ternary and quaternary aqueous electrolyte mixtures are shown in Figs. S1S4, located in the SI. In each of those multi-ion cases involving chloride, bromide, nitrate, sulfate, or any combination of these as anions, AIOMFAC-VISC performs as well or better than the Laliberte model. Given that those data sets were used in the overall fit of the AIOMFAC-VISC parameters, this is not unexpected. Nevertheless, those successful representations of multiion cases, though limited by experimental data, provide confidence in AIOMFAC-VISC's ability to predict the viscosities of multi-ion solutions of various compositions.

\subsection{Extrapolative behavior for binary aqueous electrolyte solutions at room temperature}

In Figures 4 through 7, we compare AIOMFAC-VISC predictions with extrapolations from the Laliberté model at $295 \mathrm{~K}$. Agreement between AIOMFAC-VISC and the Laliberté model is excellent within the range of available measurements for each system, which are plotted as black circles. Outside of this range, the models diverge, sometimes to a large degree. It is worth noting that crystallization is inhibited/neglected in both the AIOMFAC-VISC and the Laliberte model calculations, resulting in (mostly) smooth curves throughout the concentration range. Also, the Laliberté model occasionally depicts spurious behavior outside of the measurement range. When the Laliberté model exceeds its applicability limit, which is provided for each electrolyte in Laliberté (2007), it can sometimes produce negative viscosity values as output; on a logarithmic viscosity scale plot, these deviations are indicated by a sharp discontinuity in the viscosity curve. AIOMFAC-VISC never predicts negative viscosity values, but at exceedingly low water activity, AIOMFAC by default stops its calculations when run for a single curve covering output from dilute to concentrated conditions. This is justified since the resulting water activities at low $w_{\mathrm{w}}$ would be for conditions far beyond a realistic equilibrium RH in the atmosphere (or other environments). Water activity and $w_{\mathrm{w}}$ vary differently for different aqueous electrolyte solutions as shown by comparing the upper and lower horizontal axis of each panel; so, the exact point at which the model output was stopped is different for each aqueous electrolyte solution, but is typically below $w_{\mathrm{w}}=0.2$.

For aqueous chloride salts/acids, (Fig. 4), AIOMFAC-VISC and the Laliberté model agree closely, generally to within one order of magnitude (even outside the concentration range of the measurements). For $\mathrm{NaCl}$ and $\mathrm{LiCl}$ (Fig. 4b,c), the Laliberté model projects a near linear increase in $\log _{10}$ viscosity below the $w_{\mathrm{w}}$ threshold of the measurements, while the AIOMFACVISC predictions include a more steep increase in viscosity below $w_{\mathrm{w}}=0.4$, likely due to higher relative influence of the ionic-strength-dependent cation-anion viscosity contributions. For $\mathrm{KCl}, \mathrm{NH}_{4} \mathrm{Cl}$, and $\mathrm{MgCl}_{2}$ (Fig. 4a,d,e), the Laliberté model shows spurious behavior outside of the measurement range. In these cases, the AIOMFAC-VISC predictions are preferable because the curves remain smooth. 

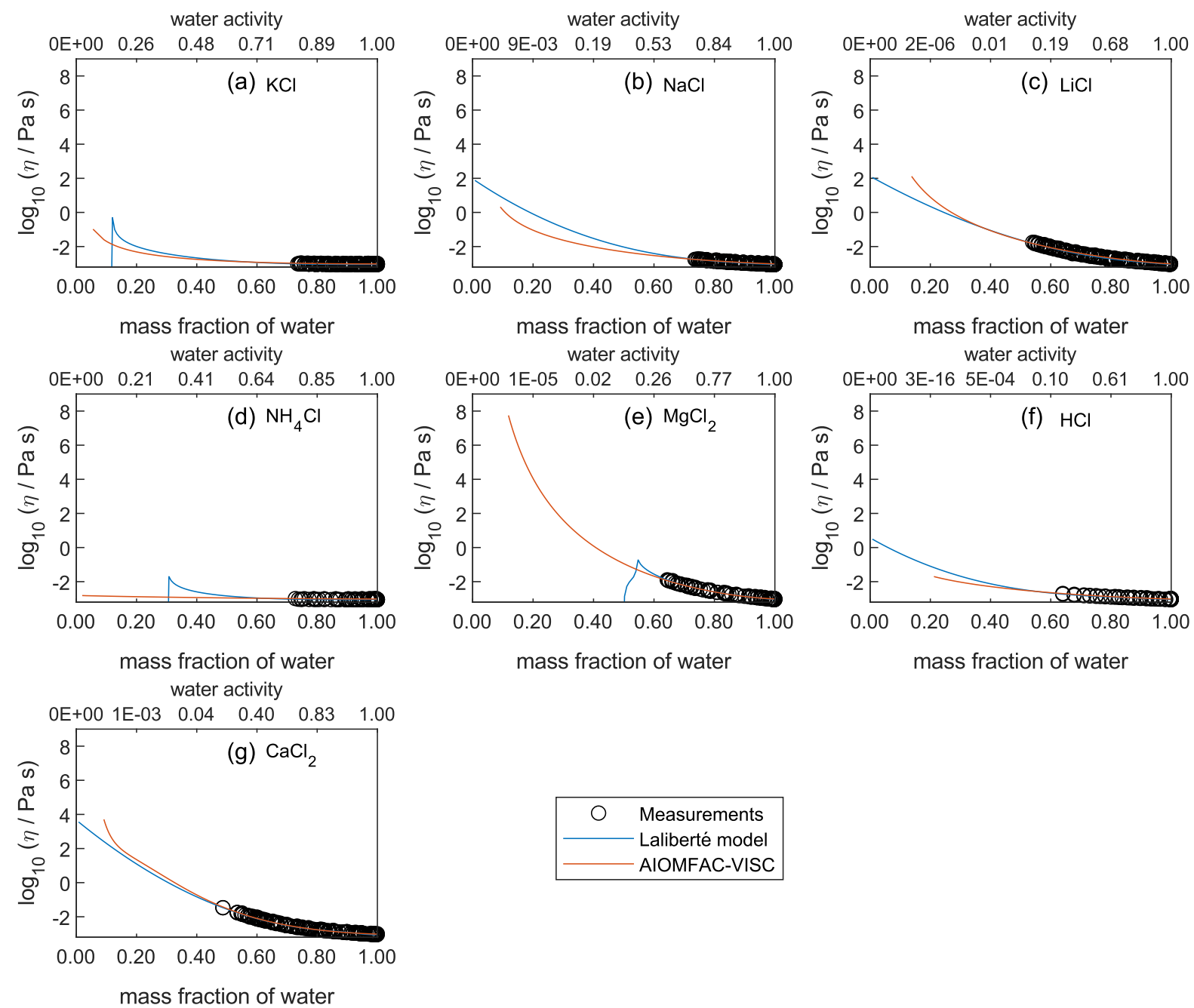

Figure 4. Comparison of the Laliberté model, AIOMFAC-VISC, and viscosity measurements versus mass fraction of water (bottom axis) and AIOMFAC-predicted water activity (top axis) for binary solutions of chloride salts at $295 \mathrm{~K}$ with measurements shown for $295 \pm 5 \mathrm{~K}$ : (a) $\mathrm{KCl}$; (b) $\mathrm{NaCl}$; (c) $\mathrm{LiCl}$; (d) $\mathrm{NH}_{4} \mathrm{Cl}$; (e) $\mathrm{MgCl}_{2}$; (f) $\mathrm{HCl}$; (g) $\mathrm{CaCl}_{2}$. Sharp discontinuities on the Laliberté model curve indicate extrapolation to non-physical values; extrapolated values should not be used beyond such points, which are outside of the valid concentration ranges provided by Laliberté (2007). AIOMFAC-VISC predictions are not shown for concentrations corresponding to exceedingly low predicted water activity $\left(a_{\mathrm{w}}<10^{-12}\right)$, so the curve sometimes stops abruptly. Neither model accounts for potential crystallization of the solute (enabling predictions for extremely high ionic strengths). The values in the top axis are rounded to two significant digits. The data sources for the measurements are listed in Table 2. 

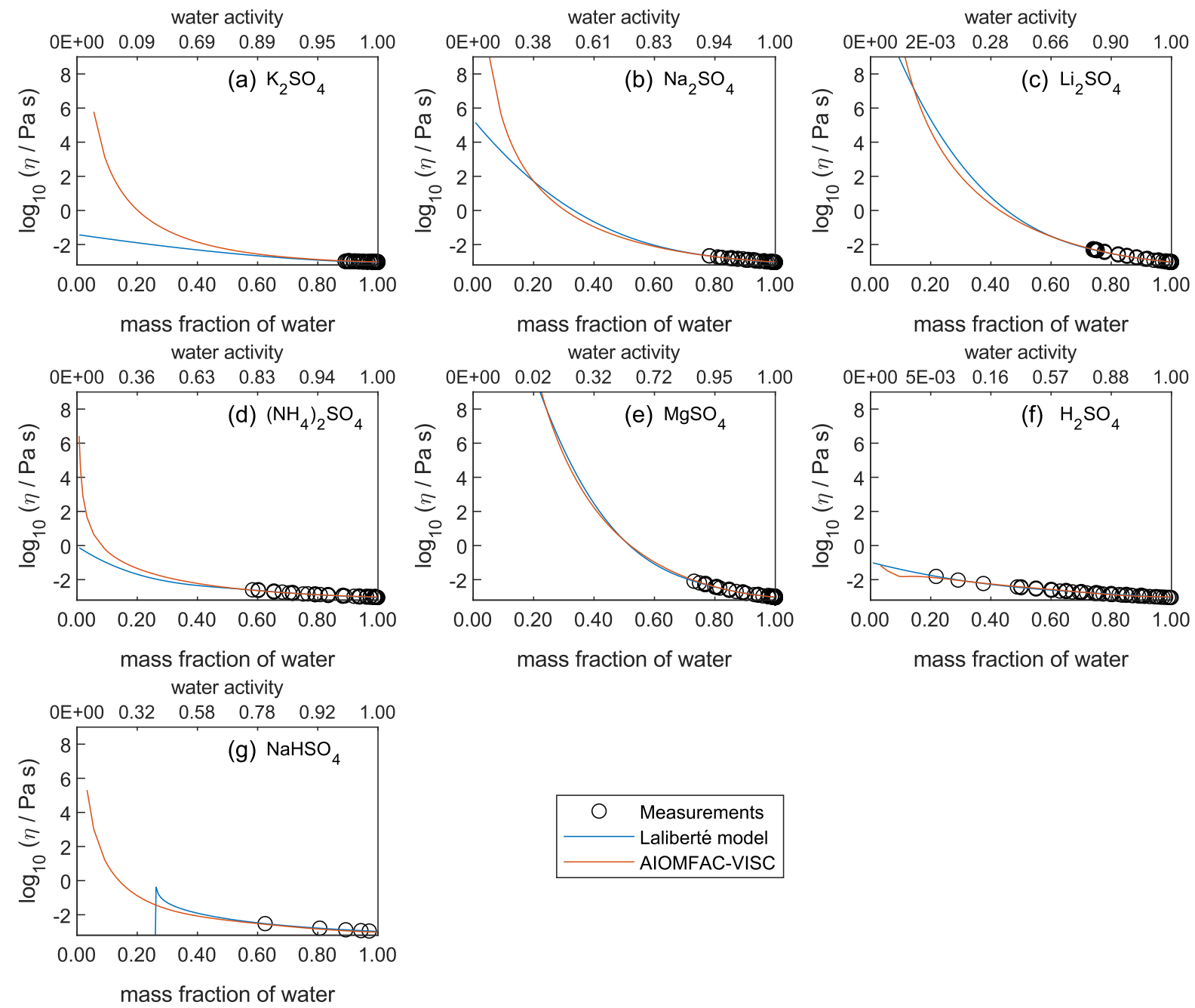

Figure 5. Comparison of the Laliberté model, AIOMFAC-VISC, and viscosity measurements versus mass fraction of water (bottom axis) and AIOMFAC-predicted water activity (top axis) for binary solutions of sulfate salts at $295 \mathrm{~K}$ with measurements shown for $295 \pm 5 \mathrm{~K}::$ (a) $\mathrm{K}_{2} \mathrm{SO}_{4}$; (b) $\mathrm{Na}_{2} \mathrm{SO}_{4}$; (c) $\mathrm{Li}_{2} \mathrm{SO}_{4}$; (d) $\left(\mathrm{NH}_{4}\right)_{2} \mathrm{SO}_{4}$; (e) $\mathrm{MgSO}_{4}$; (f) $\mathrm{H}_{2} \mathrm{SO}_{4}$; (g) $\mathrm{NaHSO}_{4}$. No measurements were available for NaHSO 4 at 298.15 K. See also caption to Fig. 4. 

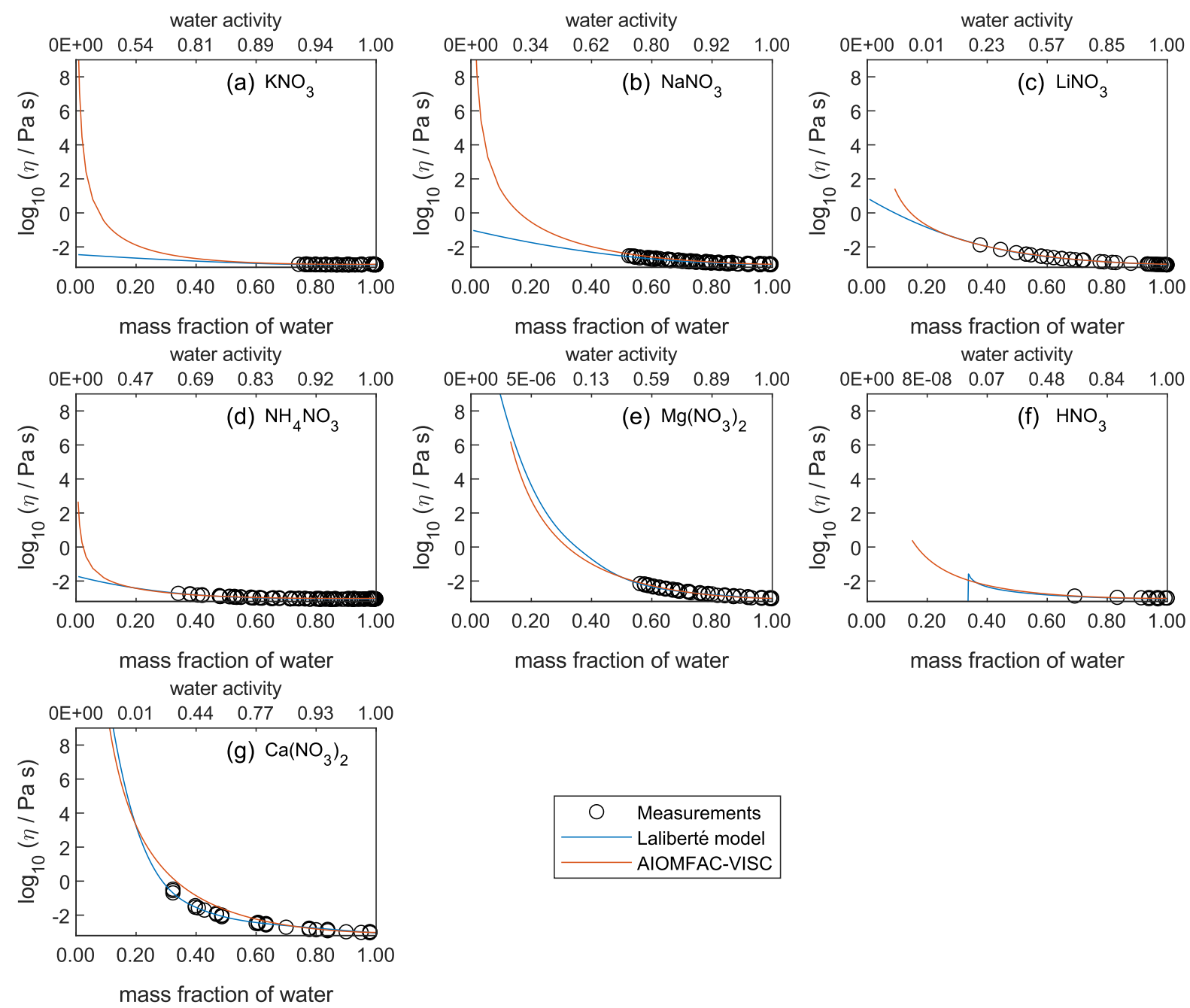

Figure 6. Comparison of the Laliberté model, AIOMFAC-VISC, and viscosity measurements versus mass fraction of water (bottom axis) and AIOMFAC-predicted water activity (top axis) for binary solutions of nitrate salts at $295 \mathrm{~K}$ with measurements shown for $295 \pm 5 \mathrm{~K}::$ (a) $\mathrm{KNO}_{3}$; (b) $\mathrm{NaNO}_{3}$; (c) $\mathrm{LiNO}_{3}$; (d) $\mathrm{NH}_{4} \mathrm{NO}_{3}$; (e) $\mathrm{Mg}\left(\mathrm{NO}_{3}\right)_{2}$; (f) $\mathrm{HNO}_{3}$; (g) $\mathrm{Ca}\left(\mathrm{NO}_{3}\right)_{2}$. See also caption to Fig. 4. 

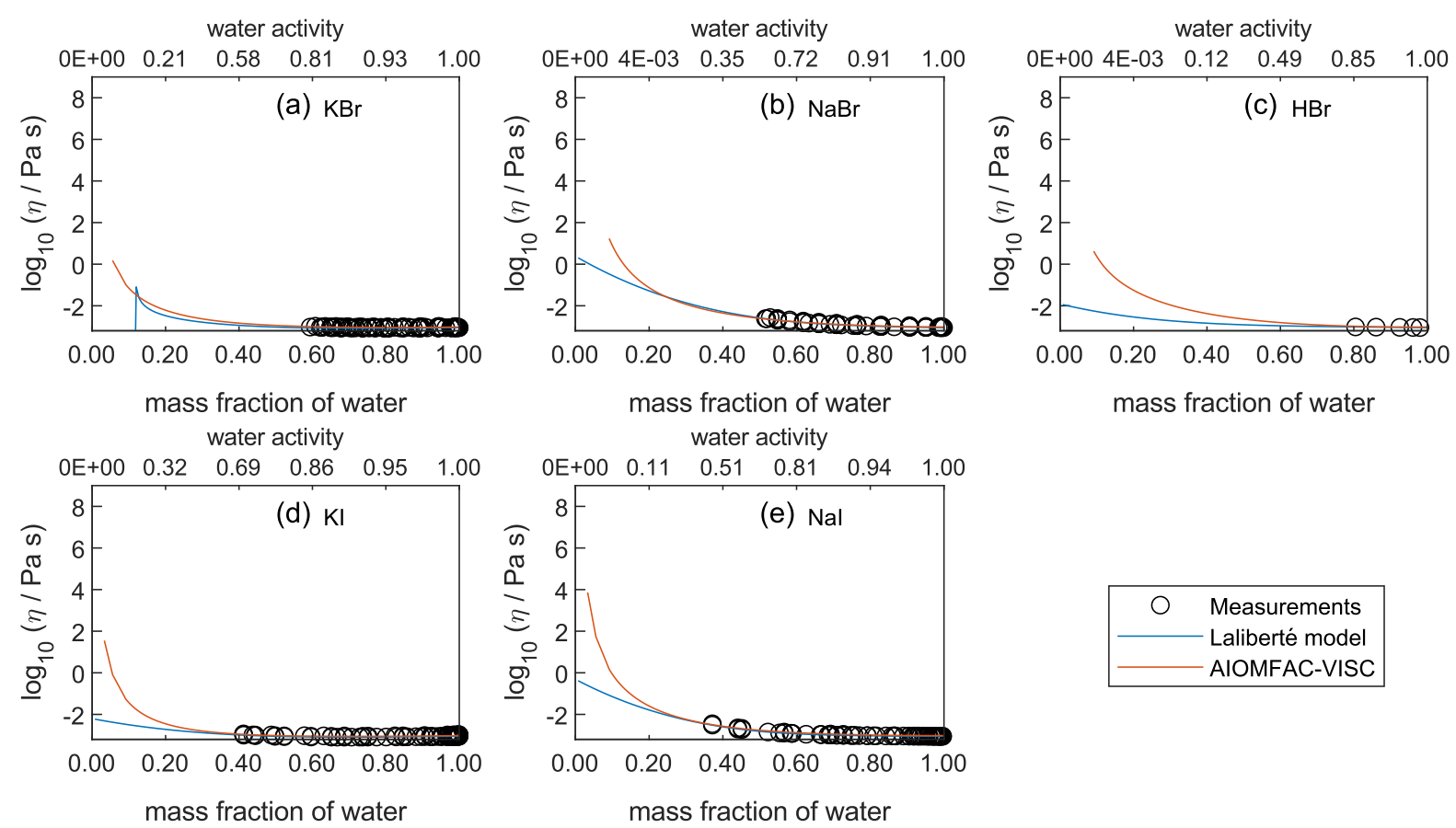

Figure 7. Comparison of the Laliberté model, AIOMFAC-VISC, and viscosity measurements versus mass fraction of water (bottom axis) and AIOMFAC-predicted water activity (top axis) for binary solutions of bromide and iodide salts at $295 \mathrm{~K}$ with measurements shown for $295 \pm 5 \mathrm{~K}$ : (a) KBr; (b) NaBr; (c) HBr; (d) KI; (e) NaI. See also caption to Fig. 4.

In Figs. 5-7, AIOMFAC-VISC and the Laliberté model continue to agree closely. The AIOMFAC-VISC curve for $\mathrm{H}_{2} \mathrm{SO}_{4}$ (Fig. 5f) includes a notch below $w_{\mathrm{w}}=0.2$, which indicates a relatively sharp change in the bisulfate dissociation degree as predicted by AIOMFAC for the sulfate-bisulfate equilibrium in that system. For $\mathrm{Ca}\left(\mathrm{NO}_{3}\right)_{2}$ (Fig. 6g), the AIOMFAC-VISC curve closely fits the measurement points, but predicts higher viscosity than the Laliberté model below $w_{\mathrm{w}}=0.4$, due to the influence of the droplet-based measurements used to fit this system; see comparison to droplet-based measurements in Figs. 8 and S5a. Figure S5 also shows AIOMFAC-VISC predictions for binary $\mathrm{HI}$ and LiBr, which are not fitted by the Laliberté model.

Due to the lack of viscosity measurements at low mass fraction of water and the tendency for salts to crystallize at high concentration, it is difficult to determine quantitatively which model/curve, if any, is correct for any given case. What is clear, however, is that AIOMFAC-VISC provides an excellent level of accuracy in the composition range where measurement data are available and can be used in place of the Laliberté model in most instances.

\subsection{Comparing AIOMFAC-VISC with aqueous inorganic aerosol surrogate mixtures}

Unlike bulk viscosity measurement techniques, which determine viscosity for known composition (e.g. mass fractions), recent aerosol and/or microscopic droplet viscosity measurement techniques characterize viscosity with respect to known equilibrium 

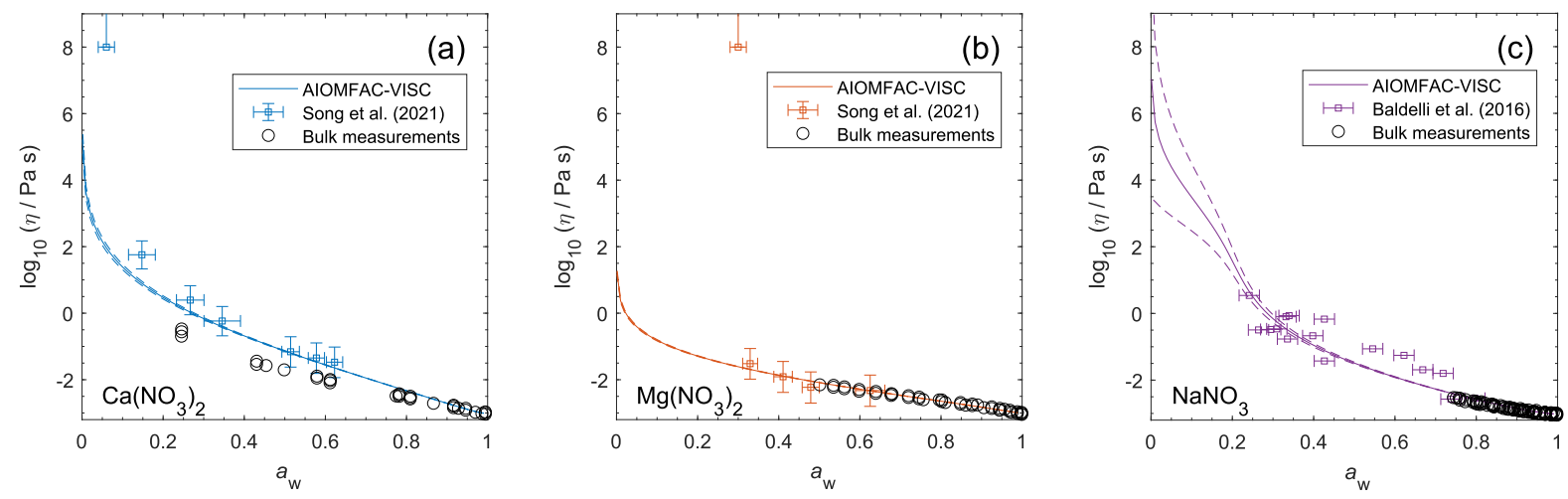

Figure 8. Viscosity predictions for aerosol surrogate mixtures containing nitrate salts at varying water activity, $a_{w}$ (RH). Model sensitivity, defined by a $2 \%$ change in aerosol water content, is shown in dashed curves. Bulk measurements (see Table 2) were collected at defined concentrations and converted to $a_{w}$ using AIOMFAC; the points collected at temperatures between $295 \pm 5 \mathrm{~K}$ are shown. Song et al. (2021) used poke-and-flow and bead mobility techniques. Baldelli et al. (2016) used holographic optical tweezers.

water activity $(\mathrm{RH})$ instead. A limited number of measurements of this type are available; we present results for three aqueous nitrate salts, $\mathrm{Ca}\left(\mathrm{NO}_{3}\right)_{2}, \mathrm{Mg}\left(\mathrm{NO}_{3}\right)_{2}$, and $\mathrm{NaNO}_{3}$.

Figure 8 shows the predicted viscosity of aqueous nitrate salts over the full RH range with AIOMFAC-VISC model sensitivity represented by the upper and lower dashed curves. AIOMFAC-VISC model sensitivity is defined by a $2 \%$ change in the aerosol water mass fraction, described in the supporting information of Gervasi et al. (2020). In the case of aqueous $\mathrm{Ca}\left(\mathrm{NO}_{3}\right)_{2}$ (Fig. 8a), disagreement between the two measurement data sets is noticed, especially at lower water activities. AIOMFACVISC shows positive bias relative to the bulk measurements, and it shows better agreement with the aerosol measurements between $a_{\mathrm{w}}=0.65$ and $a_{\mathrm{w}}=0.3$. It is possible that these bulk measurements understate viscosity for aqueous $\mathrm{Ca}\left(\mathrm{NO}_{3}\right)_{2}$, which would mean that the large model deviation for this system is not necessarily so bad. In the case of $\mathrm{Mg}\left(\mathrm{NO}_{3}\right)_{2}$ (Fig. 8b) the aerosol measurements largely agree with the bulk measurements, and AIOMFAC-VISC correctly characterizes nearly every point. In both Fig. 8a,b there is one outlying data point at low $a_{\mathrm{w}}$ with a stated viscosity value at $10^{8} \mathrm{~Pa}$. In fact, Song et al. (2021) used $10^{8} \mathrm{Pas}$ as the upper limit for their viscosity measurements. Such a high value reported may be best explained by the crystallization of $\mathrm{Ca}\left(\mathrm{NO}_{3}\right)_{2}$ or $\mathrm{Mg}\left(\mathrm{NO}_{3}\right)_{2}$, but using the poke-and-flow measurement technique, it is difficult to distinguish between glasses, gels, and crystallized aerosols. Crystallization is inhibited in the shown AIOMFAC-VISC predictions, likely explaining the divergence from those high-viscosity measurement points. Our AIOMFAC-based equilibrium model is capable of providing liquid-liquid and solid-liquid equilibrium calculations, but viscosity prediction would not be possible for the solid phase. In the case of $\mathrm{NaNO}_{3}$ (Fig. 8c), there is rather poor agreement between the bulk measurements and the aerosol measurements by Baldelli et al. (2016). At $a_{\mathrm{w}}<0.2$, the uncertainty of the AIOMFAC-VISC prediction for $\mathrm{NaNO}_{3}$ widens considerably, indicating that small changes in solution water content can greatly affect both the water activity and viscosity predictions. Indeed, a $2 \%$ change in mass fraction of water corresponds to a much larger change in water activity for $\mathrm{NaNO}_{3}$ (Fig. 6b) than for $\mathrm{Ca}\left(\mathrm{NO}_{3}\right)_{2}$ (Fig. 6e) or $\mathrm{Mg}\left(\mathrm{NO}_{3}\right)_{2}$ (Fig. 6g). This prediction indicates that $\mathrm{NaNO}_{3}$ particles of semi-solid 


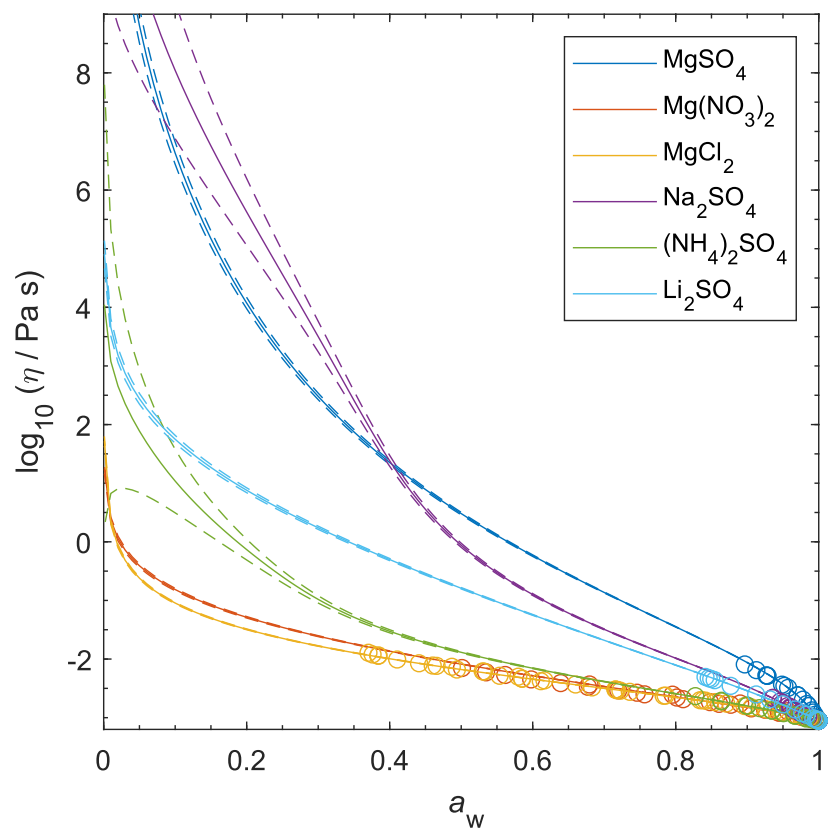

Figure 9. AIOMFAC-VISC predicted viscosity for selected binary aqueous electrolyte solutions at 298.15 K. Model sensitivity (dashed curves) shows the impact of a $2 \%$ variability in determined aerosol water content at stated water activity, $a_{\mathrm{w}}$. Bulk measurements are shown as open circles, with colors matching the prediction curves for each electrolyte.

viscosity might be observed below $\sim 20 \% \mathrm{RH}$, which corresponds to an observation of non-crystalline viscous $\mathrm{NaNO}_{3}$ in particle rebound experiments by Li et al. (2017).

Although viscosity measurements are not available, aqueous $\mathrm{MgSO}_{4}$ particles have been observed as highly viscous liquids and/or (non-Newtonian) gels ( $\mathrm{Li}$ et al., 2017; Cai et al., 2015; Richards et al., 2020a). AIOMFAC-VISC predicts high viscosity values for aqueous $\mathrm{MgSO}_{4}$, and a transition to a semi-solid viscosity below $a_{\mathrm{w}}=0.4$. Richards et al. (2020a) differentiate gels from Newtonian liquids by the presence of an abrupt change in microrheology and the lack of shape relaxation (on practical experimental timescales). It is not possible to verify these findings with the present version of AIOMFAC-VISC, which does not explicitly include consideration of liquid-to-gel phase transitions, and they clearly merit further study.

Nevertheless, the theory behind AIOMFAC-VISC can account to some extent for the unique behavior of aqueous $\mathrm{MgSO}_{4}$. $\mathrm{Mg}^{2+}$ and $\mathrm{SO}_{4}^{2-}$ are both doubly charged ions, which likely attract water molecules into long-lasting hydration shells. As RH decreases, free water molecules evaporate from the particle, leaving behind the hydrated ions. These hydrated cations and anions agglomerate, forming chains and reducing the flow of molecules. No other aqueous electrolytes that we used to fit AIOMFAC-VISC included two doubly charged ions, but we did include other electrolytes which contained either $\mathrm{Mg}^{2+}$ or $\mathrm{SO}_{4}^{2-}$, and we have plotted them alongside $\mathrm{MgSO}_{4}$ in Fig. 9. Below $a_{\mathrm{w}}=0.4$, the $\mathrm{MgSO}_{4}$ predicted viscosity is consistently higher than that of most of the other binary aqueous solutions shown by at least two orders of magnitude in viscosity, the exception being $\mathrm{Na}_{2} \mathrm{SO}_{4}$ which is expected to effloresce above $50 \% \mathrm{RH}$ (Li et al., 2017; Ahn et al., 2010). Predicted viscosities 
for the other binary aqueous solutions remain below the semi-solid threshold $\left(10^{2} \mathrm{Pas}\right)$ down to $\mathrm{RH}=10 \% . \mathrm{MgCl}_{2}$ and $\mathrm{Mg}\left(\mathrm{NO}_{3}\right)_{2}$ produce nearly identical predictions, suggesting that the effects of chloride and nitrate anions are similar, or that ion interactions in $\mathrm{MgSO}_{4}$ are more important than those of other magnesium-containing electrolytes. On the other hand, the predictions for the other sulfate-containing electrolytes differ substantially from each other. $\mathrm{Na}_{2} \mathrm{SO}_{4}$ and $\mathrm{Li}_{2} \mathrm{SO}_{4}$ produce higher predicted viscosities than $\left(\mathrm{NH}_{4}\right)_{2} \mathrm{SO}_{4}$, suggesting that the inclusion of a more charge-dense cation as the counter-ion to $\mathrm{SO}_{4}^{2-}$ results in slightly higher viscosity.

\subsection{Comparing AIOMFAC-VISC with aqueous organic-inorganic aerosol surrogate mixtures}

Room temperature measurements are available for aqueous mixtures of sucrose with $\mathrm{Ca}\left(\mathrm{NO}_{3}\right)_{2}, \mathrm{Mg}\left(\mathrm{NO}_{3}\right)_{2}$, and $\mathrm{NaNO}_{3}$. Sucrose is commonly used as a proxy for secondary organic aerosol because it has a similar oxygen-to-carbon ratio as highly oxidized organic aerosol components and viscosity and related diffusivity data are available in the literature (Evoy et al., 2019). In Fig. 10, AIOMFAC-VISC viscosity predictions are tested for these systems at varying water activity, providing a comparison of the three organic-inorganic mixing approaches described in Sect. 3.4. Each of these mixing approaches predicts viscosities between those of the relevant sucrose-free aqueous nitrate salt solution and the aqueous (salt-free) sucrose solution (plotted in grey). As the OIR increases, the mixture viscosity prediction approaches that of aqueous sucrose and as the OIR decreases, the prediction tends toward the viscosity of the aqueous nitrate salt. Figure 10a,b show cases for an OIR of 1, while Figure 10c,d are for an OIR of 1.5 and 4, respectively. The reported error in viscosity for the Song et al. (2021) measurements can be as large as an order of magnitude, much larger than the typical reported error for bulk measurements. AIOMFAC-VISC's model sensitivity is mostly contained within the width of the error bars. Viscosity error bars for Fig. 10c,d were not available.

The aquelec mixing model predictions appear to agree best with the measurements for $1: 1$ sucrose- $\mathrm{Ca}\left(\mathrm{NO}_{3}\right)_{2}$ (Fig. 10a) and 60:40 sucrose- $\mathrm{NaNO}_{3}$ (Fig. 10c), while the ZSR-style mixing rule performs best for 1:1 sucrose- $\mathrm{Mg}\left(\mathrm{NO}_{3}\right)_{2}$ (Fig. 10b) and 80:20 sucrose- $\mathrm{NaNO}_{3}$ (Fig. 10d). In Fig. 10b, aquelec predicts values within the uncertainty of the measurements between 70 and $30 \% \mathrm{RH}$, but underpredicts the measurements between 20 and $10 \% \mathrm{RH}$. The aquorg mixing model consistently predicts lower viscosity values than the other two mixing models, and this negative bias is exacerbated at low RH. The measurements for binary solutions of some salts include abrupt increases in viscosity at low RH (5\% for $\mathrm{Ca}\left(\mathrm{NO}_{3}\right)_{2}$ and $35 \%$ for $\mathrm{Mg}\left(\mathrm{NO}_{3}\right)_{2}$, as shown in Fig. 8). This could be the result of crystallization of the salt, a glass transition, or a gel transition during the experiments. Regardless, when mixed with sucrose, this abrupt viscosity increase appears to be inhibited. Richards et al. (2020b) found that ternary organic-inorganic mixtures containing certain doubly charged cations had higher viscosity than the corresponding salt-free aqueous organic mixture, but AIOMFAC-VISC would not be able to produce such results without further additions for organic-ion effects (a potential subject of future work). Of the three systems shown here, the viscosity of aqueous sucrose is consistently higher than the ternary mixture throughout the RH range. Additional AIOMFAC-VISC predictions are shown for the mixtures from (Richards et al., 2020b) in Figs. S6 and S7 .

In terms of computational speed, the ZSR mixing model takes approximately five to six times longer than aquelec or aquorg (see Tables S1 and S2 in the SI. In dynamic simulations that may require repeated calls to AIOMFAC, such as kinetic multilayer diffusion models, this time difference may be an important consideration. 

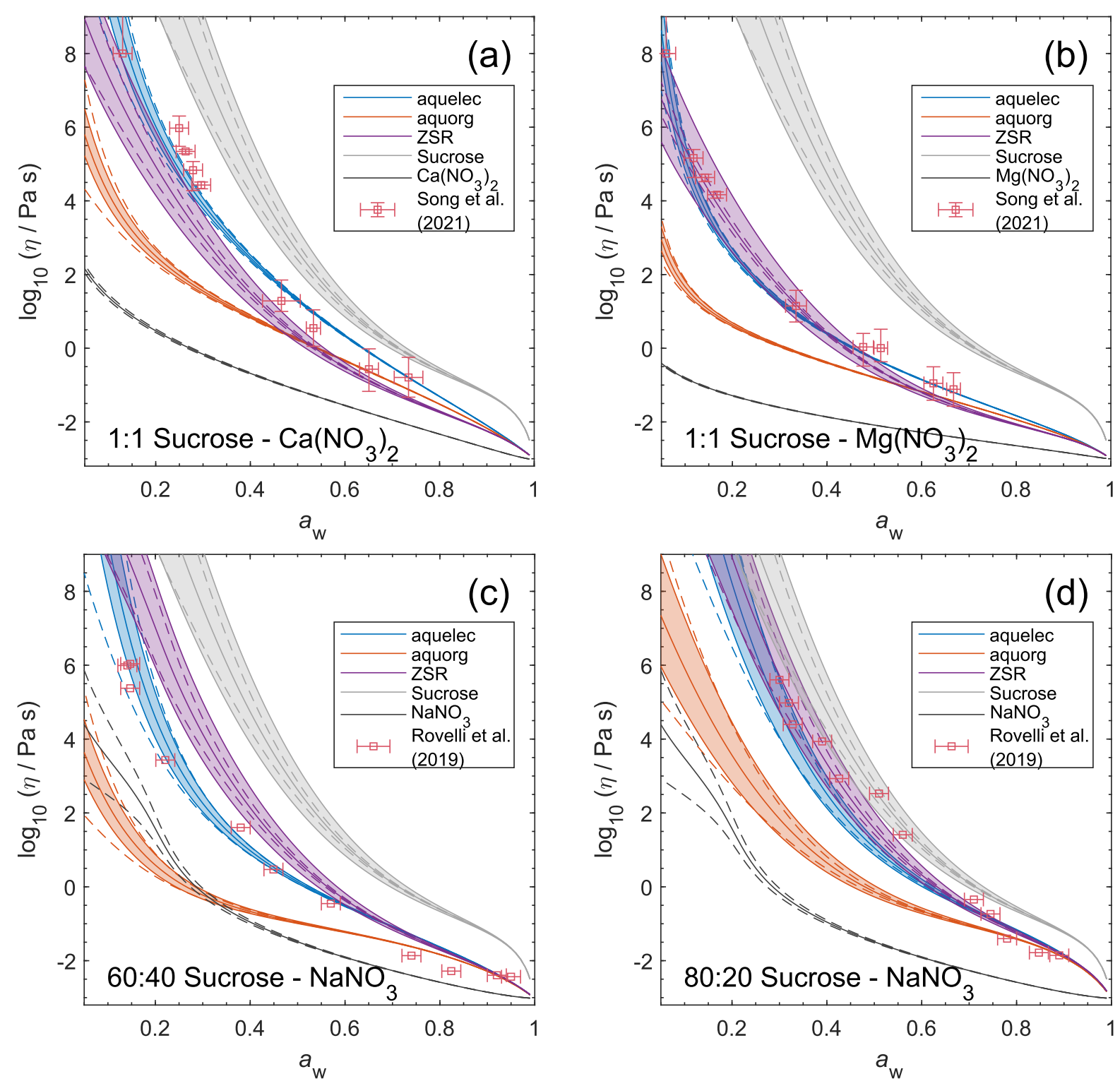

Figure 10. Viscosity predictions for aerosol surrogate mixtures containing sucrose and nitrate salts at varying water activity, $a_{w}(\mathrm{RH})$, with a prescribed organic-to-inorganic dry mass ratio (OIR). Three mixing models - aquelec, aquorg, and ZSR - are shown alongside the viscosity measurements. Model sensitivity, defined by the impact of a $2 \%$ change in aerosol water content, is shown by the dashed curves. Shaded regions show the potential viscosity prediction error introduced by a $\pm 5 \%$ error in the glass transition temperature of sucrose. AIOMFACVISC predictions are also included for the binary aqueous sucrose and aqueous nitrate salt systems, which correspond to the organic and inorganic subsystems used in each mixing model (see Sect. 3.4). 


\section{Atmospheric implications}

650

While AIOMFAC-VISC is flexibly designed to predict viscosity for bulk solution phases, in case of equilibrium gas-particle partitioning computations, it is additionally capable of calculating the viscosities of individual aerosol phases when the presence of liquid-liquid phase separation is predicted. This functionality is expected to be especially important in future research on aerosol phase state and in estimating molecular diffusion inside of aerosol particles, some of which may be multiphase particles. To illustrate the utility of AIOMFAC-VISC for atmospheric aerosol, we show how AIOMFAC-VISC can predict the viscosities of two coexisting liquid phases and compare the result to a scenario of assuming a homogeneously mixed single phase. Furthermore, we carry out predictions of the viscosities of both particle phases during the idealized adiabatic ascent of an air parcel. Finally, we show AIOMFAC-VISC predicted particle viscosity of selected aerosols equilibrated to the thermodynamic conditions reported for an atmospheric vertical profile collected at Maniwaki Station, Quebec. In the context of meteorology, the effect of changing atmospheric pressure on viscosity is expected to be negligible and is therefore ignored.

Liquid-liquid phase separation (LLPS) has been observed in aerosol particles (Bertram et al., 2011; Song et al., 2012; You et al., 2014), and capturing this behavior is essential to accurately characterizing aerosol mass concentrations. Coexisting liquid phases are expected to occur when low-polarity and highly polar organics are present in a particle and/or when inorganic ions, water and moderate to lower polarity organics are present, or when weakly oxidized SOA material partitions into an existing aqueous aerosol (e.g. Huang et al., 2021). Relatively fresh SOA of moderate to lower polarity is likely to form a second, organic-rich phase that will coexist with an aqueous ion-rich phase. By contrast, aged SOA includes organic species that are more highly oxygenated, and these species will more likely dissolve and mix with water and ions in a single liquid phase. AIOMFAC-VISC can be used to predict the viscosity of any number of condensed phases, as we have done for a mixture of $\alpha$-pinene-derived SOA and ammonium sulfate with an OIR $=1$ exhibiting two "liquid" phases over a wide range in RH (Fig. 11). In the LLPS case shown in Fig. 11a, two liquid phases are predicted, and the organic-rich phase attains a semi-solid viscosity for $\mathrm{RH}<80 \%$. When we assume a single mixed phase (Fig. 11b), the predicted viscosity is less than that of the organic-rich phase in Fig. 11a, due to the plasticizing effect of water contributed by the hygroscopic ions. A phase-separated aerosol, with a more viscous organic-rich shell, will likely be more resistant to chemical processing than a homogeneously mixed aerosol (Zhou et al., 2019). While the viscosity of the organic-rich phase becomes semi-solid (> $10^{2} \mathrm{Pas}$ ) below RH $=0.8$, the single mixed phase remains liquid-like $\left(<10^{2} \mathrm{Pas}\right)$ until $\mathrm{RH}=0.2$. The calculations for the phase viscosities in the LLPS case were carried out in two steps: first, an AIOMFAC-based coupled gas-particle and liquid-liquid equilibrium computation was performed to determine the phase compositions while not computing the viscosities in the process (since it is unnecessary) and second, AIOMFAC-VISC is run for the compositions of the determined phases to provide the viscosities and associated estimations of uncertainties. The surrogate mixture representing $\alpha$-pinene SOA is listed in Table S4 of the SI.

Figure 12 shows the predicted viscosities for phase-separated particles consisting of $\alpha$-pinene SOA and ammonium sulfate (overall OIR of 1) as a function of temperature and RH. Given an average oxygen-to-carbon ratio of about 0.5 for $\alpha$-pinene SOA, its mixture with aqueous ammonium sulfate is expected to result in nearly complete separation of the salt and SOA into distinct phases, except at RH levels exceeding $99.5 \%$ (Bertram et al., 2011; Zuend and Seinfeld, 2012). Over the same ranges 

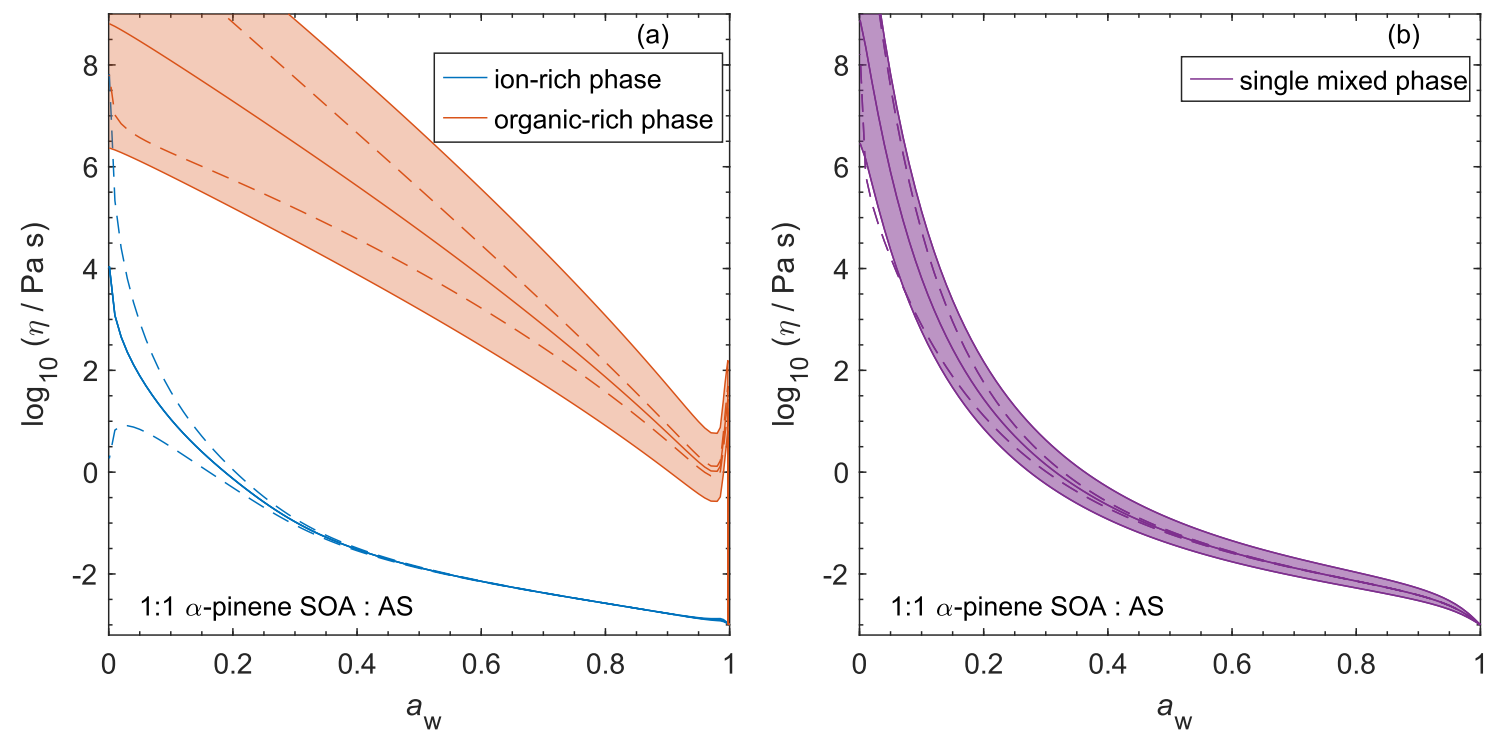

Figure 11. Viscosity predictions for aerosol surrogate mixtures containing $\alpha$-pinene SOA and ammonium sulfate at varying water activity, $a_{w}(\mathrm{RH})$, with an overall organic-to-inorganic dry mass ratio (OIR) of 1 and $T=293.15 \mathrm{~K}$. (a) Viscosities of the individual coexisting liquid phases predicted by AIOMFAC LLPS model; blue: inorganic ion-rich phase, orange: organic-rich phase. (b) Predictions for a forced single mixed phase. The aquelec mixing model is used to calculate the viscosities of the organic-inorganic mixtures. Model sensitivity, defined by the impact of a $2 \%$ change in aerosol water mass, is shown by the dashed curves. Shaded regions show the potential viscosity prediction error introduced by a $\pm 5 \%$ error in the average glass transition temperature of the individual $\alpha$-pinene SOA surrogate components.

of RH and temperature, the organic-rich phase viscosity spans 18 orders of magnitude, whereas the ion-rich phase spans only 5 orders of magnitude, with liquid-like viscosities prevailing except at $\mathrm{RH}<5 \%$. However, note that this composition and viscosity computation was conducted by assuming the ions to remain dissolved over the entire RH range. Depending on the initial conditions, such as starting with dry or deliquesced particles, ammonium sulfate could potentially be present in solid-liquid equilibrium with the organic-rich phase below $80 \% \mathrm{RH}$. Ammonium sulfate would be expected to be predominantly in a crystalline state for $\mathrm{RH}<35 \%$ (due to efflorescence), such that the predictions of the viscosity for lower RH levels in the ion-rich phase are hypothetical. Nevertheless, those viscosities are indicative of expected viscosity levels in similar aqueous ion-rich phases containing inorganic species that would less likely crystallize (such as certain nitrate salts).

Finally, we can use AIOMFAC-VISC to predict the viscosities of these two phases at different vertical levels in the atmosphere. To provide an example, we extracted temperature and relative humidity values from two sample vertical atmospheric profiles at Maniwaki, Quebec, measured on February 7, 2020, and July 1, 2020. We calculated the viscosities of the two phases for each vertical profile assuming the particles to be in equilibrium with the measured environmental conditions $(T, \mathrm{RH})$ at each altitude level (which is unlike the case of an adiabatically lifted air parcel). In Fig. 13, we show the viscosities of the organicrich and ion-rich phases plotted up to an altitude of approximately $35 \mathrm{~km}$. Examining these two profiles side-by-side provides 
(a)

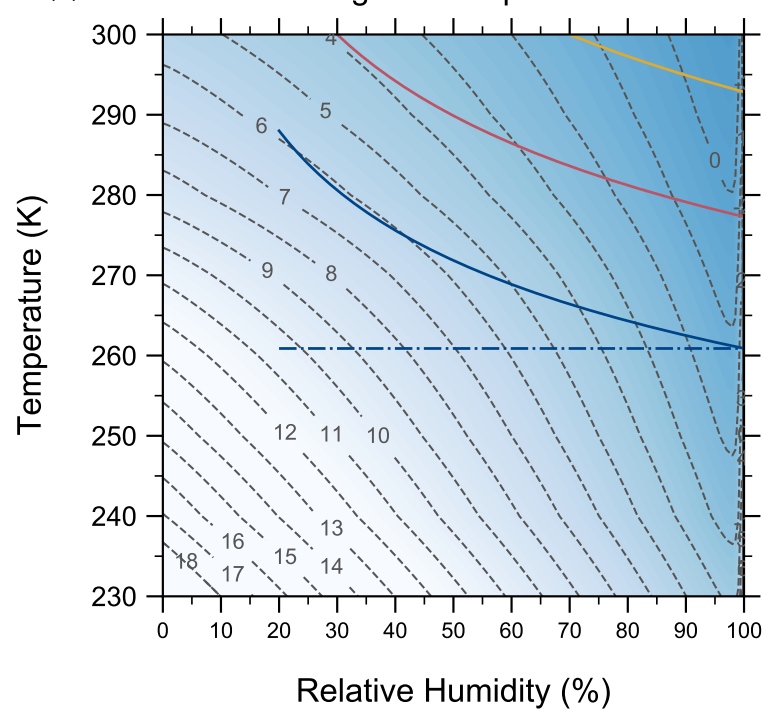

(b)

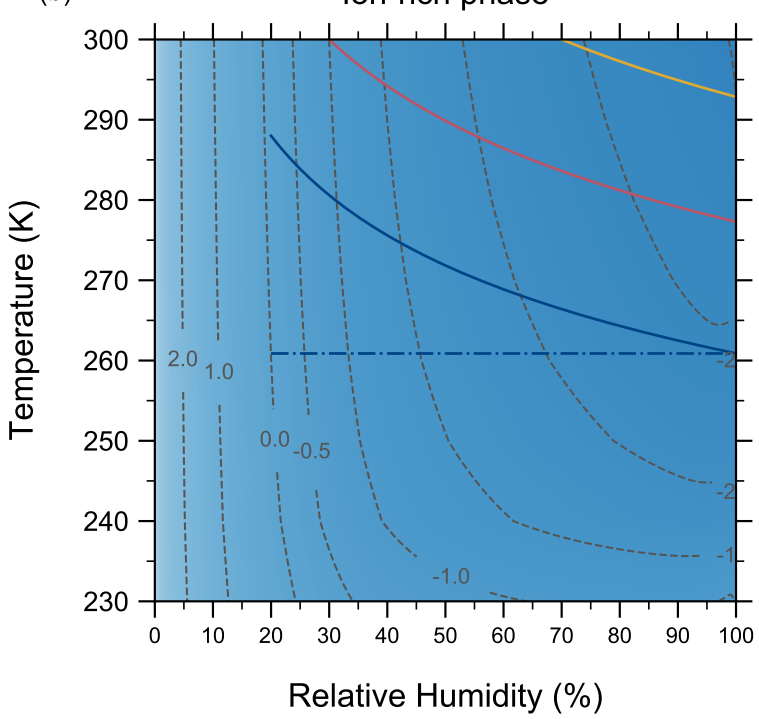

Figure 12. Viscosity predictions for coexisting phases in internally mixed aqueous $\alpha$-pinene SOA + ammonium sulfate particles with an overall OIR of 1. Dashed curves are contours of $\log _{10}(\eta /[\mathrm{Pas}])$. The three solid-colored curves represent idealized adiabatic ascent of an air parcel for different initial conditions at the surface. The prescribed initial conditions are $\mathrm{T}=288 \mathrm{~K}, \mathrm{RH}=20 \%$ (blue); $\mathrm{T}=300 \mathrm{~K}, \mathrm{RH}=$ $30 \%$ (pink); and $\mathrm{T}=300 \mathrm{~K}, \mathrm{RH}=70 \%$ (yellow). The dash-dotted blue horizontal line shows the range of RH that could be experienced by particles if they survive cloud processing and stay at the same height, while RH may change. The aquelec mixing model is used to calculate the viscosity of organic-inorganic mixtures.

useful information about the potential distribution of viscous (semi-solid) and glassy aerosol phase states in the atmosphere. As expected, the viscosity of the organic-rich phase is consistently several orders of magnitude higher than the viscosity of the aqueous ion-rich phase. The predicted viscosity for the ion-rich phase remains below $10^{4} \mathrm{~Pa}$ s throughout the vertical extent of the atmosphere. While higher liquid-state viscosities are not predicted for the ion-rich phase, freezing and efflorescence are still possible - and would likely occur at the low temperatures in the upper troposphere and lower stratosphere, with associated effects on phase state.

The February 7 sounding (Fig. 13a) was collected during a winter storm. A local maximum in the predicted viscosity is observed near the surface and corresponds to a local minimum in relative humidity between 200 and $300 \mathrm{~m}$. There is also an abrupt change in relative humidity above $12 \mathrm{~km}$, likley indicating the tropopause region. Below this altitude, there is sufficient water content in the aerosols to have a diminishing effect on the viscosity (when ignoring potential freezing and/or freezeconcentration of the phase). Above this altitude, the predicted viscosity of the organic-rich phase increases by several orders of magnitude, and it is virtually certain that SOA-rich aerosol phases at this height would be glassy. However, it is important to consider assumptions made and the example character of such calculations. They provide information about the expected viscosities that equilibrated particles of similar composition would exhibit when present at different altitude levels. We do 
not suggest that SOA-rich aerosols are typically found in the stratosphere. Wet and dry removal processes will prevent most tropospheric aerosol particles from reaching the stratosphere (Jacobson, 2002, p. 137). The July 1 sounding (Fig. 13b) was collected during a warm, moderately dry day without clouds, and the vertical profile for viscosity of the organic-rich phase shows a more gradual increase in viscosity with height. In this case, the lack of moisture in the planetary boundary layer means that the organic-rich phase attains a glassy viscosity at approximately $5 \mathrm{~km}$ altitude. The presence of glassy SOA at high altitudes has been previously hypothesized (Koop et al., 2011; Zobrist et al., 2008), and their utility as ice nuclei has been more recently established for isoprene-derived SOA (Wolf et al., 2020).

\section{Conclusions}

A new predictive model has been developed and parameterized to enable calculations of the viscosity of aqueous electrolyte solutions. Furthermore, the earlier framework for aqueous organic mixtures has been successfully coupled with the electrolyte model, providing a more general model applicable to aqueous organic-inorganic mixtures. The AIOMFAC-VISC electrolyte model is based on Eyring's absolute rate theory for viscous flow, which has been used previously to describe the viscosity of aqueous electrolyte solutions up to approximately 10 molal. A new expression for the molar Gibbs energy of activation for viscous flow for aqueous electrolyte solutions was introduced, defining contributions from individual ions and present cation-anion pairs. Forty-three aqueous electrolyte systems comprising 6,625 data points were used to simultaneously fit the AIOMFAC-VISC electrolyte model. AIOMFAC-VISC's ionic coefficients are fitted using viscosity measurements at a wide range of concentrations as opposed to classical $B$-coefficients, which were fitted at dilute conditions. AIOMFAC-VISC closely fits the available data and produces smooth predictive extrapolations, performing nearly as well as Laliberté's model, which is considered a benchmark. The parameterized AIOMFAC-VISC model also aligns with more recent measurements of aerosol surrogate mixtures containing aqueous nitrate salts.

Three mixing approaches were examined; aquelec and ZSR were found to be approximately equally accurate. The aquelec mixing approach is suggested as the preferred choice for use of AIOMFAC-VISC within dynamic (kinetic) simulations of viscosity or diffusion, because it is less computationally expensive. AIOMFAC-VISC's full functionality allows predictions for aqueous organic-inorganic mixtures consisting of an arbitrary number of organic compounds and inorganic ions. For systems that undergo phase separation according to an AIOMFAC-based liquid-liquid equilibrium computation, the viscosity of each phase can be computed once the equilibrium composition has been determined. Viscosity predictions for $\alpha$-pinene-derived SOA were discussed in the context of idealized adiabatic ascent of an air parcel and observations from two atmospheric soundings collected in Maniwaki, Quebec. Future experimental work on a wider range of compositions and a more diverse set of multicomponent systems (presently highly data-limited) may provide data and insights that could allow further refinements of the organic-inorganic mixing model. AIOMFAC-VISC may also provide an opportunity to further explore aerosol phase state and state transitions, especially gel transitions, which have become a topic of interest in laboratory aerosol studies (Song et al., 2021; Richards et al., 2020a, b). 

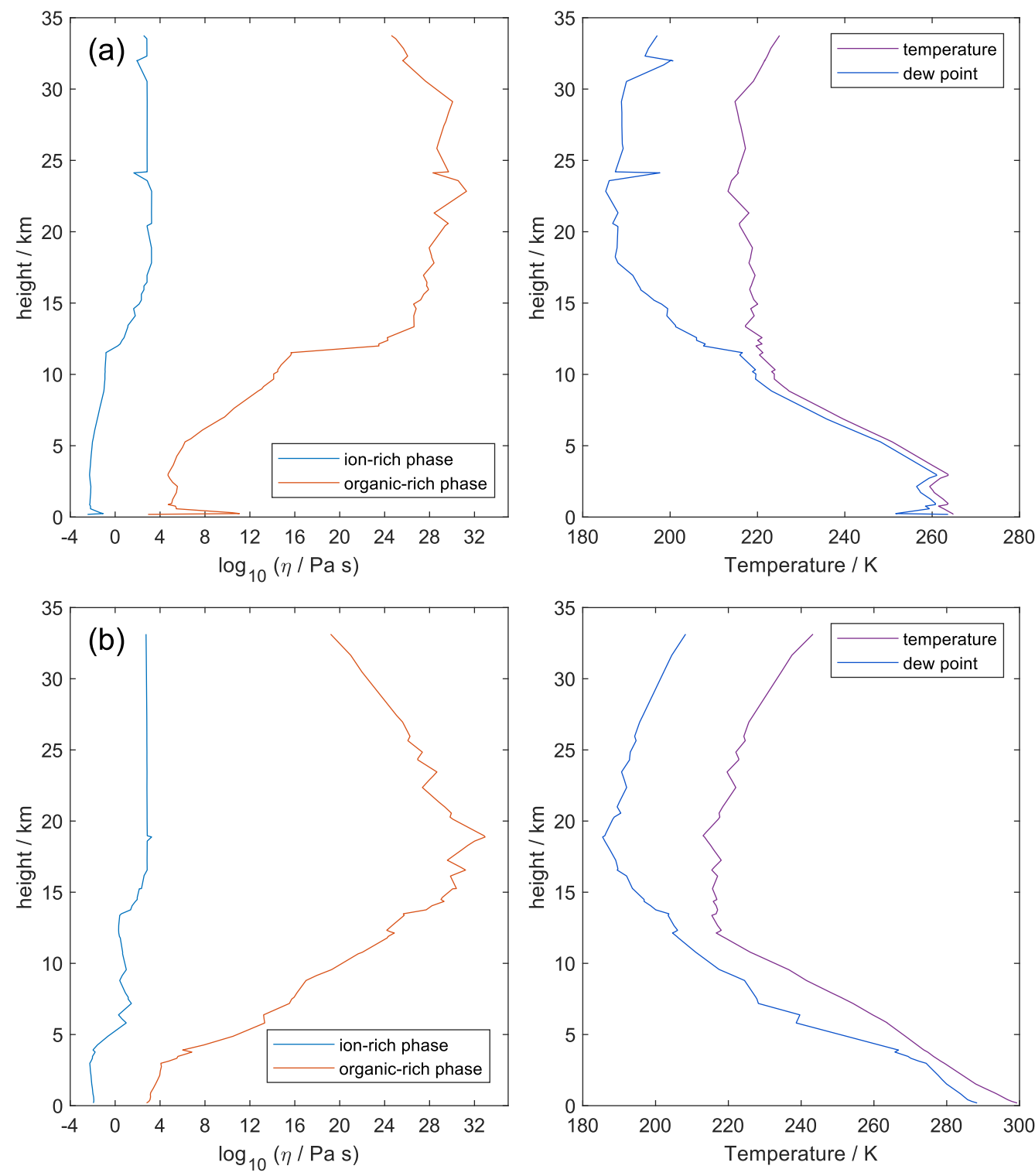

Figure 13. Viscosity predictions for observed temperature and relative humidity profiles using liquid-liquid phase separated aerosol particles containing $\alpha$-pinene SOA surrogate compounds and ammonium sulfate. Relative humidity and temperature data are taken from atmospheric soundings collected at Maniwaki, Quebec (station code: WMW) for February 7, 2020 12:00 UTC (a), and July 1, 2020 00:00 UTC (b). Left panels show AIOMFAC-VISC viscosity predictions and right panels show corresponding measurements of the air and dew point temperatures. OIR is approximately equal to 1 for warm surface conditions and increases gradually to approximately 11 for the coldest observed temperatures owing to the increased condensation of semivolatile organic compounds in this surrogate system. Sounding data is provided by the University of Wyoming (http://weather.uwyo.edu/upperair/sounding.html, accessed 4 October 2021). 
https://doi.org/10.5194/acp-2021-836

Preprint. Discussion started: 25 October 2021

(c) Author(s) 2021. CC BY 4.0 License.

(c) (1)

Code availability. The source code for AIOMFAC-VISC is contained within the code of the AIOMFAC model and an earlier version is available on Github (Zuend and Gervasi, 2019). The AIOMFAC-web model, which contains the version of AIOMFAC-VISC described in

745 Gervasi et al. (2020), can be run at https://aiomfac.lab.mcgill.ca (Zuend and Seinfeld, 2012). The new model code described in this article will be added to the same Github repository and to a future update of the AIOMFAC-web model.

Author contributions. AZ created the original research framework and provided research direction. JL established a database, analyzed the data, and created the figures. JL and AZ developed the model theory, co-wrote the software, and co-wrote the manuscript.

Competing interests. The authors declare that they have no conflict of interest.

Acknowledgements. We thank Ryan Davis, Marc Laliberté, Jonathan Reid, Young-chul Song, and Mijung Song for providing access to viscosity measurements. We also thank Thomas Preston for providing feedback on an earlier draft of the manuscript.

Financial support. This project was undertaken with financial support by the Alfred P. Sloan Foundation under prime award no. G-202013912, the government of Canada through the federal Department of Environment and Climate Change (grant no. GCXE20S049), and the Natural Sciences and Engineering Research Council of Canada (NSERC grant no. RGPIN-2021-02688). 


\section{References}

Abdulagatov, I. M., Zeinalova, A. A., and Azizov, N. D.: Viscosity of the Aqueous $\mathrm{Ca}\left(\mathrm{NO}_{3}\right)_{2}$ Solutions at Temperatures from 298 to $573 \mathrm{~K}$ and at Pressures up to $40 \mathrm{MPa}$, Journal of Chemical \& Engineering Data, 49, 1444-1450, https://doi.org/10.1021/je049853n, https://pubs.acs.org/doi/10.1021/je049853n, 2004.

Abrams, D. S. and Prausnitz, J. M.: Statistical thermodynamics of liquid mixtures: A new expression for the excess Gibbs energy of partly or completely miscible systems, AIChE Journal, 21, 116-128, https://doi.org/https://doi.org/10.1002/aic.690210115, https://aiche. onlinelibrary.wiley.com/doi/abs/10.1002/aic.690210115, _eprint: https://aiche.onlinelibrary.wiley.com/doi/pdf/10.1002/aic.690210115, 1975.

Ahn, K.-H., Kim, S.-M., Jung, H.-J., Lee, M.-J., Eom, H.-J., Maskey, S., and Ro, C.-U.: Combined Use of Optical and Electron Microscopic Techniques for the Measurement of Hygroscopic Property, Chemical Composition, and Morphology of Individual Aerosol Particles, Analytical Chemistry, 82, 7999-8009, https://doi.org/10.1021/ac101432y, https://doi.org/10.1021/ac101432y, publisher: American Chemical Society, 2010.

Bajić, D. M., Šerbanović, S. P., Živković, E. M., Jovanović, J., and Kijevčanin, M. L.: Prediction and correlation of viscosity of binary mixtures of ionic liquids with organic solvents, Journal of Molecular Liquids, 197, 1-6, https://doi.org/10.1016/j.molliq.2014.04.005, https://www.sciencedirect.com/science/article/pii/S016773221400155X, 2014.

Baldelli, A., Power, R. M., Miles, R. E. H., Reid, J. P., and Vehring, R.: Effect of crystallization kinetics on the properties of spray dried microparticles, Aerosol Science and Technology, 50, 693-704, https://doi.org/10.1080/02786826.2016.1177163, https://www.tandfonline. com/doi/full/10.1080/02786826.2016.1177163, 2016.

Bertram, A. K., Martin, S. T., Hanna, S. J., Smith, M. L., Bodsworth, A., Chen, Q., Kuwata, M., Liu, A., You, Y., and Zorn, S. R.: Predicting the relative humidities of liquid-liquid phase separation, efflorescence, and deliquescence of mixed particles of ammonium sulfate, organic material, and water using the organic-to-sulfate mass ratio of the particle and the oxygen-to-carbon elemental ratio of the organic component, Atmospheric Chemistry and Physics, 11, 10 995-11 006, https://doi.org/10.5194/acp-11-10995-2011, https://acp.copernicus.org/articles/11/10995/2011/, 2011.

Boender, C. G. E., Rinnooy Kan, A. H. G., Timmer, G. T., and Stougie, L.: A stochastic method for global optimization, Mathematical Programming, 22, 125-140, https://doi.org/10.1007/BF01581033, https://doi.org/10.1007/BF01581033, 1982.

Cai, C., Tan, S., Chen, H., Ma, J., Wang, Y., P. Reid, J., and Zhang, Y.: Slow water transport in MgSO 4 aerosol droplets at gel-forming relative humidities, Physical Chemistry Chemical Physics, 17, 29 753-29 763, https://doi.org/10.1039/C5CP05181A, https://pubs.rsc.org/ en/content/articlelanding/2015/cp/c5cp05181a, 2015.

Cox, W. M., Wolfenden, J. H., and Hartley, H. B.: The viscosity of strong electrolytes measured by a differential method, Proceedings of the Royal Society of London. Series A, Containing Papers of a Mathematical and Physical Character, 145, 475-488, https://doi.org/10.1098/rspa.1934.0113, https://royalsocietypublishing.org/doi/abs/10.1098/rspa.1934.0113, 1934.

Csendes, T.: Nonlinear parameter estimation by global optimization-efficiency and reliability, Acta Cybernetica, 8, 361-370, 1988.

Dehaoui, A., Issenmann, B., and Caupin, F.: Viscosity of deeply supercooled water and its coupling to molecular diffusion, Proceedings of the National Academy of Sciences, 112, 12 020-12 025, https://doi.org/10.1073/pnas.1508996112, http://www.pnas.org/lookup/doi/10. 1073/pnas.1508996112, 2015. 

Electrolyte Solutions, Industrial \& Engineering Chemistry Research, 40, 5021-5028, https://doi.org/10.1021/ie010392y, https://doi.org/ 10.1021/ie010392y, 2001.

Evoy, E., Maclean, A. M., Rovelli, G., Li, Y., Tsimpidi, A. P., Karydis, V. A., Kamal, S., Lelieveld, J., Shiraiwa, M., Reid, J. P., and Bertram, A. K.: Predictions of diffusion rates of large organic molecules in secondary organic aerosols using the Stokes-Einstein and fractional Stokes-Einstein relations, Atmospheric Chemistry and Physics, 19, 10 073-10 085, https://doi.org/https://doi.org/10.5194/acp-19-100732019, https://acp.copernicus.org/articles/19/10073/2019/, 2019.

Fabuss, B. M., Korosi, A., and Othmer, D. F.: Viscosities of aqueous solutions of several electrolytes present in sea water, Journal of Chemical \& Engineering Data, 14, 192-197, https://doi.org/10.1021/je60041a025, https://pubs.acs.org/doi/abs/10.1021/je60041a025, 1969.

Fard, M. M., Krieger, U. K., and Peter, T.: Kinetic Limitation to Inorganic Ion Diffusivity and to Coalescence of Inorganic Inclusions in Viscous Liquid-Liquid Phase-Separated Particles, The Journal of Physical Chemistry A, 121, 9284-9296, https://doi.org/10.1021/acs.jpca.7b05242, https://doi.org/10.1021/acs.jpca.7b05242, 2017.

Fredenslund, A., Jones, R. L., and Prausnitz, J. M.: Group-contribution estimation of activity coefficients in nonideal liquid mixtures, AIChE Journal, 21, 1086-1099, https://doi.org/https://doi.org/10.1002/aic.690210607, https://aiche.onlinelibrary.wiley.com/doi/abs/10.1002/aic. 690210607,_eprint: https://aiche.onlinelibrary.wiley.com/doi/pdf/10.1002/aic.690210607, 1975.

Fu, H., Zhang, M., Li, W., Chen, J., Wang, L., Quan, X., and Wang, W.: Morphology, composition and mixing state of individual carbonaceous aerosol in urban Shanghai, Atmospheric Chemistry and Physics, 12, 693-707, https://doi.org/10.5194/acp-12-693-2012, https://acp.copernicus.org/articles/12/693/2012/, 2012.

Gervasi, N. R., Topping, D. O., and Zuend, A.: A predictive group-contribution model for the viscosity of aqueous organic aerosol, Atmospheric Chemistry and Physics, 20, 2987-3008, https://doi.org/10.5194/acp-20-2987-2020, https://acp.copernicus.org/articles/20/2987/ 2020/, 2020.

Glasstone, S., Laidler, K., and Eyring, H.: The theory of rate processes: the kinetics of chemical reactions, viscosity, diffusion and electrochemical phenomena, McGraw-Hill, 1st ed. edn., http://hdl.handle.net/2027/uc1.b4461994, 1941.

Goldsack, D. E. and Franchetto, A. A.: The viscosity of concentrated electrolyte solutions-III. A mixture law, Electrochimica Acta, 22, 1287-1294, https://doi.org/10.1016/0013-4686(77)87012-6, https://www.sciencedirect.com/science/article/pii/0013468677870126, $8151977 \mathrm{a}$

Goldsack, D. E. and Franchetto, R.: The viscosity of concentrated electrolyte solutions. I. Concentration dependence at fixed temperature, Canadian Journal of Chemistry, 55, 1062-1072, https://doi.org/10.1139/v77-148, http://www.nrcresearchpress.com/doi/10.1139/v77-148, 1977b.

Goldsack, D. E. and Franchetto, R. C.: The viscosity of concentrated electrolyte solutions. II. Temperature dependence, Canadian Journal of Chemistry, 56, 1442-1450, https://doi.org/10.1139/v78-236, http://www.nrcresearchpress.com/doi/10.1139/v78-236, 1978.

Hallquist, M., Wenger, J. C., Baltensperger, U., Rudich, Y., Simpson, D., Claeys, M., Dommen, J., Donahue, N. M., George, C., Goldstein, A. H., Hamilton, J. F., Herrmann, H., Hoffmann, T., Iinuma, Y., Jang, M., Jenkin, M. E., Jimenez, J. L., Kiendler-Scharr, A., Maenhaut, W., McFiggans, G., Mentel, T. F., Monod, A., Prévôt, A. S. H., Seinfeld, J. H., Surratt, J. D., Szmigielski, R., and Wildt, J.: The formation, properties and impact of secondary organic aerosol: current and emerging issues, Atmospheric Chemistry and Physics, 9, 5155-5236, https://doi.org/10.5194/acp-9-5155-2009, https://acp.copernicus.org/articles/9/5155/2009/, 2009.

Heald, C. L. and Kroll, J. H.: The fuel of atmospheric chemistry: Toward a complete description of reactive organic carbon, Science Advances, 6, eaay8967, https://doi.org/10.1126/sciadv.aay8967, https://advances.sciencemag.org/content/6/6/eaay8967, 2020. 
Hu, Y.-F. and Lee, H.: Prediction of viscosity of mixed electrolyte solutions based on the Eyring's absolute rate theory and the semi-ideal hydration model, Electrochimica Acta, 48, 1789-1796, https://doi.org/10.1016/S0013-4686(03)00226-3, http://www.sciencedirect.com/ science/article/pii/S0013468603002263, 2003.

Huang, Y., Mahrt, F., Xu, S., Shiraiwa, M., Zuend, A., and Bertram, A. K.: Coexistence of three liquid phases in individual atmospheric aerosol particles, Proceedings of the National Academy of Sciences, 118, https://doi.org/10.1073/pnas.2102512118, https://www.pnas. org/content/118/16/e2102512118, iSBN: 9782102512117 Publisher: National Academy of Sciences Section: Physical Sciences, 2021.

Iyoki, S., Iwasaki, S., Kuriyama, Y., and Uemura, T.: Densities, viscosities, and surface tensions for the two ternary systems water + lithium bromide + lithium iodide + lithium chloride + lithium nitrate, Journal of Chemical \& Engineering Data, 38, 302-305, https://doi.org/10.1021/je00010a031, https://pubs.acs.org/doi/abs/10.1021/je00010a031, 1993.

Jacobson, M. Z.: Air pollution and global warming: history, science, and solutions, Cambridge University Press, 2002.

Jenkins, H. D. B. and Marcus, Y.: Viscosity B-Coefficients of Ions in Solution, Chemical Reviews, 95, 2695-2724, https://doi.org/10.1021/cr00040a004, https://pubs.acs.org/doi/abs/10.1021/cr00040a004, 1995.

Jones, G. and Dole, M.: The viscosity of aqueous solutions of strong electrolytes with special reference to barium chloride, Journal of the American Chemical Society, 51, 2950-2964, https://doi.org/10.1021/ja01385a012, https://doi.org/10.1021/ja01385a012, 1929.

Kaminsky, M.: Untersuchungen über die Wechselwirkung Ion-Lösungsmittel, insbesondere auf Grund von Viskositätsmessungen, Zeitschrift für Naturforschung A, 12, 424-433, https://doi.org/10.1515/zna-1957-0511, https://www.degruyter.com/document/doi/10. 1515/zna-1957-0511/html, publisher: Verlag der Zeitschrift für Naturforschung Section: Zeitschrift für Naturforschung A, 1957.

Kiriukhin, M. Y. and Collins, K. D.: Dynamic hydration numbers for biologically important ions, Biophysical Chemistry, 99, 155-168, https://doi.org/10.1016/S0301-4622(02)00153-9, https://www.sciencedirect.com/science/article/pii/S0301462202001539, 2002.

Koop, T., Bookhold, J., Shiraiwa, M., and Pöschl, U.: Glass transition and phase state of organic compounds: dependency on molecular properties and implications for secondary organic aerosols in the atmosphere, Physical Chemistry Chemical Physics, 13, 19238-19255, https://doi.org/10.1039/C1CP22617G, https://pubs.rsc.org/en/content/articlelanding/2011/cp/c1cp22617g, 2011.

Laliberté, M.: Model for Calculating the Viscosity of Aqueous Solutions, Journal of Chemical \& Engineering Data, 52, 321-335, https://doi.org/10.1021/je0604075, https://doi.org/10.1021/je0604075, 2007.

Laliberté, M.: A Model for Calculating the Heat Capacity of Aqueous Solutions, with Updated Density and Viscosity Data, Journal of Chemical \& Engineering Data, 54, 1725-1760, https://doi.org/10.1021/je8008123, https://pubs.acs.org/doi/10.1021/je8008123, 2009.

Lencka, M. M., Anderko, A., Sanders, S. J., and Young, R. D.: Modeling Viscosity of Multicomponent Electrolyte Solutions, International Journal of Thermophysics, 19, 367-378, https://doi.org/10.1023/A:1022501108317, https://doi.org/10.1023/A:1022501108317, 1998.

Li, Y.-J., Liu, P.-F., Bergoend, C., Bateman, A. P., and Martin, S. T.: Rebounding hygroscopic inorganic aerosol particles: Liquids, gels, and hydrates, Aerosol Science and Technology, 51, 388-396, https://doi.org/10.1080/02786826.2016.1263384, https://www.tandfonline.com/ doi/full/10.1080/02786826.2016.1263384, 2017.

Marcus, Y.: Effect of ions on the structure of water: structure making and breaking, Chemical reviews, 109, 1346-1370, 2009.

860 Miller, A.: Global optimization using the Boender-Timmer-Rinnoy Kan algorithm, https://www.mat.univie.ac.at/ neum/glopt/contrib/global. f90, https://www.mat.univie.ac.at/ neum/glopt/contrib/global.f90, 2003.

Moré, J. J., Garbow, B. S., and Hillstrom, K. E.: User guide for MINPACK-1, Tech. rep., CM-P00068642, 1980.

Moré, J. J., Sorensen, D. C., Hillstrom, K., and Garbow, B.: The MINPACK project, Sources and development of mathematical software, 25, 88-111, 1984. 
Nishikata, E., Ishii, T., and Ohta, T.: Viscosities of aqueous hydrochloric acid solutions, and densities and viscosities of aqueous hydroiodic acid solutions, Journal of Chemical \& Engineering Data, 26, 254-256, https://doi.org/10.1021/je00025a008, https://pubs.acs.org/doi/abs/ 10.1021/je00025a008, 1981.

Nowlan, M.-F., Doan, T. H., and Sangster, J.: Prediction of the viscosity of mixed electrolyte solutions from single-salt data, The Canadian Journal of Chemical Engineering, 58, 637-642, https://doi.org/10.1002/cjce.5450580514, https://onlinelibrary.wiley.com/doi/abs/10.1002/ cjce.5450580514,_eprint: https://onlinelibrary.wiley.com/doi/pdf/10.1002/cjce.5450580514, 1980.

Prather, K. A., Bertram, T. H., Grassian, V. H., Deane, G. B., Stokes, M. D., DeMott, P. J., Aluwihare, L. I., Palenik, B. P., Azam, F., Seinfeld, J. H., Moffet, R. C., Molina, M. J., Cappa, C. D., Geiger, F. M., Roberts, G. C., Russell, L. M., Ault, A. P., Baltrusaitis, J., Collins, D. B., Corrigan, C. E., Cuadra-Rodriguez, L. A., Ebben, C. J., Forestieri, S. D., Guasco, T. L., Hersey, S. P., Kim, M. J., Lambert, W. F., Modini, R. L., Mui, W., Pedler, B. E., Ruppel, M. J., Ryder, O. S., Schoepp, N. G., Sullivan, R. C., and Zhao, D.: Bringing the ocean into the laboratory to probe the chemical complexity of sea spray aerosol, Proceedings of the National Academy of Sciences, 110, 7550-7555, https://doi.org/10.1073/pnas.1300262110, https://www.pnas.org/content/110/19/7550, publisher: National Academy of Sciences Section: Physical Sciences, 2013.

Pye, H. O. T., Zuend, A., Fry, J. L., Isaacman-VanWertz, G., Capps, S. L., Appel, K. W., Foroutan, H., Xu, L., Ng, N. L., and Goldstein, A. H.: Coupling of organic and inorganic aerosol systems and the effect on gas\&ndash;particle partitioning in the southeastern US, Atmospheric Chemistry and Physics, 18, 357-370, https://doi.org/10.5194/acp-18-357-2018, https://acp.copernicus.org/articles/18/357/2018/, 2018.

Pye, H. O. T., Nenes, A., Alexander, B., Ault, A. P., Barth, M. C., Clegg, S. L., Collett Jr., J. L., Fahey, K. M., Hennigan, C. J., Herrmann, H., Kanakidou, M., Kelly, J. T., Ku, I.-T., McNeill, V. F., Riemer, N., Schaefer, T., Shi, G., Tilgner, A., Walker, J. T., Wang, T., Weber, R., Xing, J., Zaveri, R. A., and Zuend, A.: The acidity of atmospheric particles and clouds, Atmospheric Chemistry and Physics, 20, 4809-4888, https://doi.org/10.5194/acp-20-4809-2020, https://acp.copernicus.org/articles/20/4809/2020/, 2020.

Reid, J. P., Bertram, A. K., Topping, D. O., Laskin, A., Martin, S. T., Petters, M. D., Pope, F. D., and Rovelli, G.: The viscosity of atmospherically relevant organic particles, Nature Communications, 9, 956, https://doi.org/10.1038/s41467-018-03027-z, https: //www.nature.com/articles/s41467-018-03027-z, 2018.

Richards, D. S., Trobaugh, K. L., Hajek-Herrera, J., and Davis, R. D.: Dual-Balance Electrodynamic Trap as a Microanalytical Tool for Identifying Gel Transitions and Viscous Properties of Levitated Aerosol Particles, Analytical Chemistry, 92, 3086-3094, https://doi.org/10.1021/acs.analchem.9b04487, https://pubs.acs.org/doi/10.1021/acs.analchem.9b04487, 2020a.

Richards, D. S., Trobaugh, K. L., Hajek-Herrera, J., Price, C. L., Sheldon, C. S., Davies, J. F., and Davis, R. D.: Ion-molecule interactions enable unexpected phase transitions in organic-inorganic aerosol, Science Advances, 6, eabb5643, https://doi.org/10.1126/sciadv.abb5643, https://advances.sciencemag.org/content/6/47/eabb5643, 2020b.

Roy, M. N., Jha, A., and Choudhury, A.: Densities, Viscosities and Adiabatic Compressibilities of Some Mineral Salts in Water at Different Temperatures, Journal of Chemical \& Engineering Data, 49, 291-296, https://doi.org/10.1021/je030205y, https://pubs.acs.org/doi/10. 1021/je030205y, 2004.

Shannon, R. D.: Revised Effective Ionic Radii and Systematic Studies of Interatomic Distances in Halides and Chaleogenides, Acta Crystallogr., Sect. A, 32, 751-767, https://doi.org/10.1107/S0567739476001551, 1976.

Shiraiwa, M. and Seinfeld, J. H.: Equilibration timescale of atmospheric secondary organic aerosol partitioning, Geophysical Research Letters, 39, https://doi.org/10.1029/2012GL054008, https://agupubs.onlinelibrary.wiley.com/doi/abs/10.1029/2012GL054008, _eprint: https://agupubs.onlinelibrary.wiley.com/doi/pdf/10.1029/2012GL054008, 2012. 
Shiraiwa, M., Zuend, A., Bertram, A. K., and Seinfeld, J. H.: Gas-particle partitioning of atmospheric aerosols: interplay of physical state, non-ideal mixing and morphology, Physical Chemistry Chemical Physics, 15, 11 441, https://doi.org/10.1039/c3cp51595h, http://xlink. rsc.org/?DOI=c3cp51595h, 2013.

Song, M., Marcolli, C., Krieger, U. K., Zuend, A., and Peter, T.: Liquid-liquid phase separation in aerosol particles: Dependence on O:C, organic functionalities, and compositional complexity, Geophysical Research Letters, 39, https://doi.org/10.1029/2012GL052807,_ https://agupubs.onlinelibrary.wiley.com/doi/abs/10.1029/2012GL052807, _eprint: https://agupubs.onlinelibrary.wiley.com/doi/pdf/10.1029/2012GL052807, 2012.

Song, Y.-C., Lilek, J., Lee, J. B., Chan, M. N., Wu, Z., Zuend, A., and Song, M.: Viscosity and phase state of aerosol particles consisting of sucrose mixed with inorganic salts, Atmospheric Chemistry and Physics, 21, 10 215-10 228, https://doi.org/10.5194/acp-21-10215-2021, https://acp.copernicus.org/articles/21/10215/2021/, 2021.

Stokes, R. H. and Robinson, R. A.: Interactions in aqueous nonelectrolyte solutions .i. Solute-solvent equilibria, J. Phys. Chem., 70, 2126$2130,1966$.

Storn, R. and Price, K.: Differential Evolution - A Simple and Efficient Heuristic for global Optimization over Continuous Spaces, Journal of Global Optimization, 11, 341-359, https://doi.org/10.1023/A:1008202821328, https://doi.org/10.1023/A:1008202821328, 1997.

Wahab, A. and Mahiuddin, S.: Isentropic Compressibility and Viscosity of Aqueous and Methanolic Calcium Chloride Solutions, Journal of Chemical \& Engineering Data, 46, 1457-1463, https://doi.org/10.1021/je0100721, https://pubs.acs.org/doi/10.1021/je0100721, 2001.

Wallace, B. J. and Preston, T. C.: Water Uptake and Loss in Viscous Aerosol Particles with Concentration-Dependent Diffusivities, The Journal of Physical Chemistry A, 123, 3374-3382, https://doi.org/10.1021/acs.jpca.9b00907, https://doi.org/10.1021/acs.jpca.9b00907, 2019.

Wang, P., Anderko, A., and Young, R. D.: Modeling viscosity of concentrated and mixed-solvent electrolyte systems, Fluid Phase Equilibria, 226, 71-82, https://doi.org/10.1016/j.fluid.2004.09.008, https://www.sciencedirect.com/science/article/pii/S0378381204004352, 2004.

Wimby, J. M. and Berntsson, T. S.: Viscosity and density of aqueous solutions of lithium bromide, lithium chloride, zinc bromide, calcium chloride and lithium nitrate. 1. Single salt solutions, Journal of Chemical \& Engineering Data, 39, 68-72, https://doi.org/10.1021/je00013a019, https://pubs.acs.org/doi/abs/10.1021/je00013a019, 1994.

Wolf, M. J., Zhang, Y., Zawadowicz, M. A., Goodell, M., Froyd, K., Freney, E., Sellegri, K., Rösch, M., Cui, T., Winter, M., Lacher, L., Axisa, D., DeMott, P. J., Levin, E. J. T., Gute, E., Abbatt, J., Koss, A., Kroll, J. H., Surratt, J. D., and Cziczo, D. J.: A biogenic secondary organic aerosol source of cirrus ice nucleating particles, Nature Communications, 11, 4834, https://doi.org/10.1038/s41467-020-18424-6, https://www.nature.com/articles/s41467-020-18424-6, 2020.

Yin, H., Dou, J., Klein, L., Krieger, U. K., Bain, A., Wallace, B. J., Preston, T. C., and Zuend, A.: Extension of the AIOMFAC model by iodine and carbonate species: applications for aerosol acidity and cloud droplet activation, Atmospheric Chemistry and Physics Discussions, pp. 1-57, https://doi.org/10.5194/acp-2021-636, https://acp.copernicus.org/preprints/acp-2021-636/, publisher: Copernicus GmbH, 2021.

You, Y., Smith, M. L., Song, M., Martin, S. T., and Bertram, A. K.: Liquid-liquid phase separation in atmospherically relevant particles consisting of organic species and inorganic salts, International Reviews in Physical Chemistry, 33, 43-77, https://doi.org/10.1080/0144235X.2014.890786, https://doi.org/10.1080/0144235X.2014.890786, publisher: Taylor \& Francis _eprint: https://doi.org/10.1080/0144235X.2014.890786, 2014.

Zdanovskii, A. B.: Untitled, Tr. Solyanoi Lab. Akad. Nauk SSSR, pp. 5-70, 1936.

Zdanovskii, A. B.: New methods of calculating solubilities of electrolytes in multicomponent systems, Zh. Fiz. Khim., 22, 1478-1485, 1948. 
Zhang and Han: Viscosity and Density of Water + Sodium Chloride + Potassium Chloride Solutions at 298.15 K, Journal of Chemical \&

Engineering Data, 41, 516-520, https://doi.org/10.1021/je9501402, https://pubs.acs.org/doi/10.1021/je9501402, 1996.

Zhang, H.-L., Chen, G.-H., and Han, S.-J.: Viscosity and Density of $\mathrm{H} 2 \mathrm{O}+\mathrm{NaCl}+\mathrm{CaCl} 2$ and $\mathrm{H} 2 \mathrm{O}+\mathrm{KCl}+\mathrm{CaCl} 2$ at $298.15 \mathrm{~K}, \mathrm{Journal}$ of Chemical \& Engineering Data, 42, 526-530, https://doi.org/10.1021/je9602733, https://doi.org/10.1021/je9602733, 1997.

Zhang, Q., Jimenez, J. L., Canagaratna, M. R., Allan, J. D., Coe, H., Ulbrich, I., Alfarra, M. R., Takami, A., Middlebrook, A. M., Sun, Y. L., Dzepina, K., Dunlea, E., Docherty, K., DeCarlo, P. F., Salcedo, D., Onasch, T., Jayne, J. T., Miyoshi, T., Shimono, A., Hatakeyama, S., Takegawa, N., Kondo, Y., Schneider, J., Drewnick, F., Borrmann, S., Weimer, S., Demerjian, K., Williams, P., Bower, K., Bahreini, R., Cottrell, L., Griffin, R. J., Rautiainen, J., Sun, J. Y., Zhang, Y. M., and Worsnop, D. R.: Ubiquity and dominance of oxygenated species in organic aerosols in anthropogenically-influenced Northern Hemisphere midlatitudes, Geophysical Research Letters, 34, https://doi.org/https://doi.org/10.1029/2007GL029979, https://agupubs.onlinelibrary.wiley.com/doi/abs/10.1029/2007GL029979,_eprint: https://agupubs.onlinelibrary.wiley.com/doi/pdf/10.1029/2007GL029979, 2007.

Zhou, S., Hwang, B. C. H., Lakey, P. S. J., Zuend, A., Abbatt, J. P. D., and Shiraiwa, M.: Multiphase reactivity of polycyclic aromatic hydrocarbons is driven by phase separation and diffusion limitations, Proceedings of the National Academy of Sciences, 116, 11658 11 663, https://doi.org/10.1073/pnas.1902517116, https://www.pnas.org/content/116/24/11658, publisher: National Academy of Sciences Section: Physical Sciences, 2019.

Zobrist, B., Marcolli, C., Pedernera, D. A., and Koop, T.: Do atmospheric aerosols form glasses?, Atmos. Chem. Phys., p. $24,2008$.

Zuend, A. and Gervasi, N. R.: AIOMFAC-web v2.31 - Public model code repository (last access: 6 March 2020), https://github.com/ andizuend/AIOMFAC, 2019.

Zuend, A. and Seinfeld, J. H.: Modeling the gas-particle partitioning of secondary organic aerosol: the importance of liquid-liquid phase separation, Atmospheric Chemistry and Physics, 12, 3857-3882, https://doi.org/10.5194/acp-12-3857-2012, https://acp.copernicus.org/ articles/12/3857/2012/, 2012.

Zuend, A., Marcolli, C., Luo, B. P., and Peter, T.: A thermodynamic model of mixed organic-inorganic aerosols to predict activity coefficients, Atmos. Chem. Phys., p. 35, 2008.

Zuend, A., Marcolli, C., Peter, T., and Seinfeld, J. H.: Computation of liquid-liquid equilibria and phase stabilities: implications for RH-dependent gas/particle partitioning of organic-inorganic aerosols, Atmospheric Chemistry and Physics, 10, 7795-7820, https://doi.org/10.5194/acp-10-7795-2010, https://acp.copernicus.org/articles/10/7795/2010/, 2010.

Zuend, A., Marcolli, C., Booth, A. M., Lienhard, D. M., Soonsin, V., Krieger, U. K., Topping, D. O., McFiggans, G., Peter, T., and Seinfeld, J. H.: New and extended parameterization of the thermodynamic model AIOMFAC: calculation of activity coefficients for organicinorganic mixtures containing carboxyl, hydroxyl, carbonyl, ether, ester, alkenyl, alkyl, and aromatic functional groups, Atmospheric Chemistry and Physics, 11, 9155-9206, https://doi.org/https://doi.org/10.5194/acp-11-9155-2011, https://acp.copernicus.org/articles/11/ 9155/2011/, 2011. 